\title{
Cued for risk: Evidence for an incentive sensitization framework to explain the interplay between stress and anxiety, substance abuse, and reward uncertainty in disordered gambling behavior
}

\author{
Samantha N. Hellberg ${ }^{1,2} \cdot$ Trinity I. Russell $^{1,3} \cdot$ Mike J. F. Robinson $^{1}$ (D)
}

Published online: 24 October 2018

(C) Psychonomic Society, Inc. 2018

\begin{abstract}
Gambling disorder is an impairing condition confounded by psychiatric co-morbidity, particularly with substance use and anxiety disorders. Yet, our knowledge of the mechanisms that cause these disorders to coalesce remains limited. The Incentive Sensitization Theory suggests that sensitization of neural "wanting" pathways, which attribute incentive salience to rewards and their cues, is responsible for the excessive desire for drugs and cue-triggered craving. The resulting hyper-reactivity of the "wanting' system is believed to heavily influence compulsive drug use and relapse. Notably, evidence for sensitization of the mesolimbic dopamine pathway has been seen across gambling and substance use, as well as anxiety and stress-related pathology, with stress playing a major role in relapse. Together, this evidence highlights a phenomenon known as cross-sensitization, whereby sensitization to stress, drugs, or gambling behaviors enhance the sensitivity and dopaminergic response to any of those stimuli. Here, we review the literature on how cue attraction and reward uncertainty may underlie gambling pathology, and examine how this framework may advance our understanding of co-mordidity with substance-use disorders (e.g., alcohol, nicotine) and anxiety disorders. We argue that reward uncertainty, as seen in slot machines and games of chance, increases dopaminergic activity in the mesolimbic pathway and enhances the incentive value of reward cues. We propose that incentive sensitization by reward uncertainty may interact with and predispose individuals to drug abuse and stress, creating a mechanism through which co-mordidity of these disorders may emerge.
\end{abstract}

Keywords Addiction $\cdot$ Gambling $\cdot$ Anxiety $\cdot$ Incentive Sensitization $\cdot$ Nicotine $\cdot$ Alcohol

\section{Introduction}

Gambling is a global health concern affecting nearly 1.8 billion individuals worldwide (Shaffer \& Hall, 2001). The legalization of gambling across much of the USA has made these activities more readily accessible, from scratch cards in convenience stores to slot machine simulations online and on smartphones (King, Delfabbro, Zwaans, \& Kaptsis, 2013; Petry \& Blanco, 2013). In the USA, 85\% of adults engage in gambling at some point in their lifetime (Cunningham-

Mike J. F. Robinson

mjrobinson@wesleyan.edu

1 Psychology Department and the Neuroscience and Behavior Program, Wesleyan University, 207 High Street, Middletown, CT 06457, USA

2 University of North Carolina Chapel Hill, Chapel Hill, NC, USA

3 National Institutes on Drug Abuse, Baltimore, MD, USA
Williams et al., 2005; Kessler et al., 2008; Shaffer \& Hall, 2001). For most, gambling is a pastime that occurs in various social contexts; however, for a subset of individuals, gambling behavior becomes a debilitating and costly activity (Slutske, Piasecki, Blaszczynski, \& Martin, 2010; Slutske, Zhu, Meier, \& Martin, 2011). Gambling disorder (GD) is a behavioral addiction characterized by persistent and recurrent gambling behavior that is problematic and impairs quality of life (American Psychiatric Association, 2013; J. E. Grant, Williams, \& Kim, 2006). The estimated prevalence of GD parallels that of other major psychiatric disorders like schizophrenia (1.1\%), obsessive compulsive disorder $(1.0 \%)$, and anorexia $(0.6 \%)$, with an average prevalence rate of approximately $2.3 \%$ across countries (Kessler, Chiu, Demler, \& Walters, 2005; Kessler et al., 2008). Furthermore, subclinical gambling is estimated to impact approximately $12 \%$ of the population (CunninghamWilliams et al., 2005; Kessler et al., 2008), and thus gambling pathology represents a particularly widespread behavioral health concern. 
The prevalence of gambling pathology is particularly alarming considering the significant financial, social, mental, and physical impairments strongly associated with clinical and subthreshold gambling behavior (Potenza, Fiellin, Heninger, Rounsaville, \& Mazure, 2002). Substantial financial losses are often accompanied by poor work performance, job loss, and bankruptcy, further increasing the financial burden of gambling on the individual and society (Gerstein, Hoffmann, \& Larison, 1999). Individuals with gambling pathology report significantly higher rates of suicidal ideation, suicide attempts, divorce, arrest, spousal abuse, smoking, and physical health concerns, such as cardiac arrest (Petry \& Kiluk, 2002; Petry, Stinson, \& Grant, 2005; Potenza et al., 2002; Weinberger et al., 2015). Furthermore, gambling disorder frequently co-occurs with substance-use disorders, particularly alcohol and nicotine, as well as mood and anxiety disorders (Conway, Compton, Stinson, \& Grant, 2006; B. F. Grant et al., 2004b; Petry et al., 2005; Ronzitti, Kraus, Hoff, \& Potenza, 2018). This breadth of impairments has motivated research to better understand the biopsychosocial factors that pose risk for the onset and maintenance of gambling behaviors and co-mordid pathology.

One such body of research has examined how individual differences in the attribution of incentive salience, or "wanting," to rewards and reward-related cues may contribute to the development and persistence of gambling pathology (M. J. F. Robinson \& Berridge, 2015; M. J. F. Robinson, Fischer, Ahuja, Lesser, \& Maniates, 2015b; Rømer Thomsen, Fjorback, Møller, \& Lou, 2014). The incentive sensitization theory has afforded valuable insight into the neurobiological and behavioral processes that are associated with individual vulnerability to addictive spectrum pathology, such as substance-use disorders (T. E. Robinson \& Berridge, 1993) and, more recently, gambling disorder (Linnet, 2014; M. J. F. Robinson, Fischer, Ahuja, Lesser, \& Maniates, 2015b; Rømer Thomsen et al., 2014). However, little research has examined the co-mordidity that exists between gambling, substance use, and anxiety or stress-related disorders through this framework. Here, we review the literature on how individual differences in cue-reactivity may confer risk for gambling pathology and interact with causal processes of sensitization and cross-sensitization by reward uncertainty, drugs of abuse, and anxiety through an integrative model of incentive sensitization. We also examine how this conceptualization may advance our understanding of co-mordidity with substance-use disorders (particularly alcohol and nicotine) and anxiety disorders, highlighting potential transdiagnostic neurobiological mechanisms underlying these complex clinical presentations.

\section{Co-morbidity in gambling disorder}

Gambling disorder often co-occurs with psychiatric disorders, particularly substance use and anxiety disorders (el-Guebaly et al., 2006; Kessler et al., 2008; Lorains, Cowlishaw, \& Thomas, 2011; Parhami, Mojtabai, Rosenthal, Afifi, \& Fong, 2014). The high rates of co-mordidity between these disorders have provided support on a broad level for an overlap in vulnerability and maintenance factors between anxiety, substance use, and gambling disorders.

\section{Prevalent co-morbid conditions}

\section{Substance-use disorders}

Substance-use disorders are one of the most frequently encountered co-mordid conditions in gambling disorder (K.-L. Chou \& Afifi, 2011; Lorains et al., 2011; Walther, Morgenstern, \& Hanewinkel, 2012). In particular, alcohol and nicotine are the most often misused substances among individuals with gambling pathology (Petry et al., 2005). A recent meta-analysis including 11 studies conducted between 1998 and 2010 reported an average co-mordidity rate of 28.1\% (range: $9.9-73.2 \%$ ) for alcohol-use disorders and 60.1\% (range: $34.9-76.3 \%$ ) for nicotine dependence in individuals with subthreshold or clinical gambling severity (Lorains et al., 2011; Petry et al., 2005). Of note, there was a considerable range in the reported prevalence of these comorbidities due to notable differences in sample size, diagnostic assessment method, gambling disorder and problem gambling diagnostic criteria, and geographic location. Though this limitation is important to acknowledge, the evidence suggests that the rates of alcohol- and nicotine-use disorders in individuals with gambling-related pathology largely exceed those reported in the general population (alcohol: $8.5 \%$; nicotine: $12.8 \%$ ) (Kessler et al., 2005). Similarly, individuals with nicotine- or alcohol-related substance-use disorders are also more likely to meet the diagnostic criteria for GD compared to the general population (Krmpotich et al., 2015; Petry et al., 2005; Rennert et al., 2014). This consistently reported comordidity between substance-use disorders and gambling pathology has suggested that these syndromes may emerge from overlapping vulnerability factors, which cause them to often cohere in clinical presentations.

\section{Anxiety disorders}

In addition to substance-use disorders, anxiety disorders often present concurrently with gambling pathology. Approximately $37 \%$ (range: $14.0-60.3 \%$ ) of subthreshold and clinical gamblers suffer from an anxiety disorder (Kessler et al., 2008; Lorains et al., 2011; Petry et al., 2005), and approximately $18 \%$ of individuals with substance-use disorders meet the past 12-month criteria for an anxiety disorder (B. F. Grant et al., 2004b). In contrast, Grant and colleagues report a 12-month prevalence of $11.10 \%$ for any anxiety disorder in the general US population (B. F. Grant et al., 2004b). Additionally, models 
adjusted to account for a breadth of sociodemographic vulnerability factors (i.e., age, race/ethnicity, sex, education, income, marital status, geographic region) have demonstrated that individuals with alcohol-use disorders or nicotine dependence are on average at two to three times greater risk for an anxiety disorder in the past 12 months compared to individuals without these conditions (B. F. Grant et al., 2004b; B. F. Grant, Hasin, Chou, Stinson, \& Dawson, 2004a; Hasin, Stinson, Ogburn, \& Grant, 2007). Taken together, these findings suggest that anxiety disorders may also share vulnerability factors and mechanisms with addictive spectrum disorders. Though not within the scope of the present review, it is noteworthy that these findings extend to mood disorders as well, which are also far more prevalent among individuals with gambling or substanceuse disorders than among the general population.

It is important to note that considerable sex differences have been highlighted in the co-mordidity of gambling with anxiety and mood disorders. Mirroring the increased prevalence of anxiety disorders amongst women in the general population (e.g. Generalized Anxiety Disorder: $\mathrm{M}=1.26 \% ; \mathrm{F}=2.79 \%$ ), females with gambling disorder report disproportionately higher rates of anxiety disorders than males $(\mathrm{M}=3.94 \% ; \mathrm{F}=14.53 \%)$ (Desai \& Potenza, 2008; Kessler et al., 1994). Additionally, the lifetime prevalence of anxiety disorders in females with clinical gambling involvement $(61.93 \%)$ is much greater than that observed for women in the general population (30\%) (Blanco, Hasin, Petry, Stinson, \& Grant, 2006; J. E. Grant et al., 2006; Kessler et al., 2005). Shared diatheses between anxiety and gambling disorder may thus be particularly pertinent to female presentations.

Stressful events across the lifetime, and particularly in childhood, have been implicated in conferring vulnerability for the onset of anxiety- and stress-related conditions (McLaughlin, Conron, Koenen, \& Gilman, 2010). In fact, childhood adversity and trauma exposure (e.g., abuse, neglect) are transdiagnostically associated with the onset of psychopathology for anxiety and substance use (J. G. Green et al., 2010) as well as gambling pathology (Felsher, Derevensky, \& Gupta, 2004). Childhood adversity and trauma exposure may thus link these disorders together in co-mordid presentations by triggering or sensitizing shared neurobiological vulnerability factors. Though this pathway has been highlighted as a potential shared diathesis, the complex biopsychosocial mechanisms through which childhood adversity and stressful life events confer risk for these disorders remain largely unknown.

\section{The impact of co-morbidity}

\section{Temporal relationships between clinical gambling, substance use, and anxiety}

Though the high prevalence of co-mordid gambling, substance use, and anxiety disorders indicates a potential association between these conditions, these cross-sectional findings fail to provide specific insight into the pathways from which this relationship may emerge. For that reason, several longitudinal studies have examined the temporal onset of these disorders in relation to each other (K.-L. Chou \& Afifi, 2011; elGuebaly et al., 2006; Parhami et al., 2014). Notably, gambling involvement, even at recreational levels, has been shown to predict the onset of anxiety or substance-use disorders 3 years later (Parhami et al., 2014). Furthermore, the more severe the baseline gambling involvement, the more likely the individual was to experience the onset of either an anxiety or a substanceuse disorder. For gambling disorder and substance-use disorders, it appears this relationship is bi-directional, as the presence of one of either of these conditions often predicts the onset of the other (Afifi, Nicholson, Martins, \& Sareen, 2016; Kessler et al., 2008). These findings not only support the notion that gambling and substance use pathology may have significantly overlapping mechanisms, but also suggest that aspects of repeated gambling or substance use may actively confer risk for one another through biological, behavioral, or environmental pathways.

Anxiety disorders, however, often precede the onset of gambling disorder or substance-use disorders (Blanco et al., 2015; Kausch, Rugle, \& Rowland, 2006; Kessler et al., 2008). The high incidence of substance-use disorders in individuals with anxiety and stress-related disorders has been strongly associated with self-medication, suggesting that individuals with stress-related conditions may be more vulnerable to misuse substances to cope with aversive affective states (J. Robinson, Sareen, Cox, \& Bolton, 2011). Similarly, individuals with anxiety disorders often report gambling to cope, providing an active pathway through which anxiety may lead to problematic gambling and alcohol use as a maladaptive emotion regulation strategy (Blaszczynski \& Nower, 2002; Milosevic \& Ledgerwood, 2010). The onset of a co-mordid anxiety or substance-use disorder has been significantly associated with endorsing gambling disorder diagnostic criteria (e.g., "gambling as an escape from negative affect"), supporting the notion that coping may play a significant role in the co-mordidity between anxiety, substance use, and gambling disorders (Lister, Milosevic, \& Ledgerwood, 2015; Parhami et al., 2014). However, neural and biological pathways through which anxiety disorders may actively increase risk for addictive spectrum disorders remain largely unknown.

\section{Co-morbidity potentiates clinical severity}

In addition to these temporal linkages in the onset of clinical gambling, substance use, co-mordidities, the co-occurrence of these conditions may influence their severity. For example, individuals with alcohol- or nicotine-related substance-use disorders often present with more severe gambling behaviors and involvement (Desai \& Potenza, 2008; el-Guebaly et al., 2006; J. E. Grant \& Potenza, 2005; Ladd \& Petry, 2003; Petry 
\& Oncken, 2002). Similarly, individuals with gambling disorder demonstrate elevated substance-abuse symptoms compared to those without this condition (K.-L. Chou \& Afifi, 2011; el-Guebaly et al., 2006; Parhami et al., 2014; Possemato et al., 2015). Further, the presence of an anxiety disorder has been associated with more severe symptomatology in both gambling and substance use (C. L. Green, Nahhas, Scoglio, \& Elman, 2017; Ledgerwood \& Petry, 2006; Najavits, Meyer, Johnson, \& Korn, 2011; Possemato et al., 2015). In line with these findings, individuals with both anxiety and substance-use disorders are at the highest risk to develop moderate to severe gambling behaviors, compared to those with one or neither of these disorders (el-Guebaly et al., 2006). In accordance with these trends in symptom severity, greater social, financial, and behavioral difficulties have been observed in gamblers who smoke or misuse alcohol, indicating significantly elevated impairments in functioning (McGrath \& Barrett, 2009; Moghaddam, Yoon, Campos, \& Fong, 2015; Potenza et al., 2004).

Building upon these findings, a "dose-dependent" relationship has been cited between anxiety, substance use, and gambling disorders, whereby the severity of the anxiety symptomatology is positively associated with that of the substance use or gambling disorder (Desai \& Potenza, 2008; Giddens, Stefanovics, Pilver, Desai, \& Potenza, 2012). These effects do not appear to be merely the result of shared environmental risk factors, as supported by the work of Petry and colleagues, which reported that alcohol-use disorders were significantly related to gambling disorder even after controlling for sociodemographic variables highly associated with the risk for gambling pathology, including ethnicity, age, sex, marital status, and region of origin (Petry et al., 2005). Collectively, these findings suggest that there may be considerable overlap in the factors that confer risk for gambling, substance use, and anxiety disorders, as well as shared causal mechanisms and maintenance factors that cause these disorders to cohere and bi-directionally exacerbate symptom severity.

\section{Overlapping biopsychosocial risks factors}

It is important to note that a variety of biological, neural, genetic, and psychological/environmental factors may also constitute risk factors and contribute to the co-mordidity between gambling and substance-abuse disorder (Crockford \& el-Guebaly, 1998; Nautiyal, Okuda, Hen, \& Blanco, 2017; Wareham \& Potenza, 2010). For example, depression, bipolar disorder, and personality disorders are also highly co-mordid with gambling and substance-abuse disorders (Bergamini et al., 2018; Edens \& Rosenheck, 2011; Kennedy et al., 2010). In addition, individuals with gambling disorder may have biological or behavioral vulnerability factors that confer an elevated risk for anxiety or substance-use disorders (Ledgerwood \& Petry, 2010; Leeman \& Potenza, 2012;
Milosevic \& Ledgerwood, 2010; Walther et al., 2012). Moreover, studies in support of the classification of gambling disorder as a "behavioral addiction" have produced robust evidence for behavioral, cognitive, and biological similarities between gambling disorder and substance-use disorders ( $\mathrm{Di}$ Nicola et al., 2015; Leeman \& Potenza, 2012, 2013; Potenza, 2008; Slutske, Ellingson, Richmond-Rakerd, Zhu, \& Martin, 2013). Here we focus on anxiety disorder and chronic stress since their prevalent co-mordidity and shared risks factors hint at the possible existence of shared neural pathways and neuroadaptations implicated in the confluence of these disorders. A study examining lifetime trauma history amongst pathological gamblers found that $64 \%$ of gamblers reported a history of emotional trauma, $40.5 \%$, physical trauma, and $24.3 \%$, sexual trauma, with the majority of these traumatic events occurring in childhood and a history of trauma being associated with greater frequency of drug and alcohol dependence (Kausch et al., 2006). This evidence points to a possible common underlying cause for the coherence of anxiety, gambling, and substance-use disorders; one where the neuroadaptations associated with a history of stress and trauma might predispose certain individuals to the onset of one or more of these disorders and interact with neurobiological vulnerabilities, resulting in complex co-mordid presentations with markedly elevated symptom severity and impairment.

\section{The incentive sensitization theory}

\section{Dissociating "wanting" and "liking"}

The incentive sensitization theory provides a psychological framework and a common neural currency to explain the development of substance use and gambling disorders. It also indicates how the emergence and persistence of these disorders can be related to stress and anxiety. The incentive sensitization theory (T. E. Robinson \& Berridge, 1993, 2008) was initially proposed to distinguish between the different components of reward. It partitioned reward into "liking," "wanting," and learning, with an important focus on the distinction between "liking" and "wanting." Whereas "liking" accounts for the objective hedonic and pleasurable response to rewards, the primary focus is placed on "wanting." "Wanting" represents the visceral motivation and attraction attributed to a reward and reward-related cues. Often referred to as incentive salience, it is the psychological process by which rewards and the cues associated with them become imbued with subconscious motivational value and are transformed into objects of desire (M. J. F. Robinson, Robinson, \& Berridge, 2013; T. E. Robinson \& Berridge, 1993, 2008). The attribution of incentive salience is a psychological process mediated by mesocorticolimbic systems in the brain that help direct behavior towards naturally sought-after rewards, such as food, 
water, and sex. It heightens perception and focuses attention towards the particular sights, sounds, and smells associated with these rewards in a way that adaptively promotes wellbeing and survival (Hickey \& Peelen, 2015).

"Wanting" and "liking" typically fluctuate in unison, where "liking" a particular reward renders it commensurately "wanted." However, under particular circumstances such as drug addiction, "liking" and "wanting" can be dissociated, where "wanting" may even occur despite the fact that the user might not subjectively enjoy the reward itself (Berridge \& Robinson, 2003; Berridge, Robinson, \& Aldridge, 2009). In fact, certain highly addictive drugs such as nicotine are exceedingly "wanted" despite producing little to no feelings of pleasure or euphoria (Benowitz, 1996; Isomura, Suzuki, \& Murai, 2014; West, 2009), and drug self-administration can be maintained in the absence of any subjective pleasure (Fischman \& Foltin, 1992). This evidence supports the view that subjective pleasure does not play a necessary causal role in drug-taking behavior. In particular, following repeated exposure to drugs of abuse, which progressively increases "wanting" and desire for more drug (Vezina, 2004; Vezina, Lorrain, Arnold, Austin, \& Suto, 2002), individuals tend to escalate their consumption by increasing both the frequency with which drug is taken and the quantity consumed during each drug-taking episode. This increased urge for the drug is due to a sensitization of the neural pathways responsible for "wanting" (Ferrario \& Robinson, 2007; Ferrario et al., 2005). This process, known as incentive sensitization, renders individuals hyper-responsive to drugs and their cues. It sensitizes the incentive value attributed to drugs, but also particularly to the cues that have been associated with the drug. In turn these cues can become motivational magnets that attract attention and trigger intense bouts of craving and desire to seek and take their associated drug reward (M. J. F. Robinson et al., 2013; M. J. F. Robinson, Fischer, Ahuja, Lesser, \& Maniates, 2015b). However, repeated drug intake does not appear to produce a sensitization of "liking" (Bartlett, Hallin, Chapman, \& Angrist, 1997). Instead, the pleasure that is often derived from taking a particular drug becomes dissociated from the amount to which it is "wanted." While in some cases repeated drug use results in no change in drug "liking," it can also undergo tolerance, where the hedonic response to drug tends to gradually decrease with repeated use. Similar findings suggesting blunted euphoria and response in opioid systems thought to be involved in "liking" has been reported in individuals with gambling problems (Mick et al., 2016). This dissociation between "liking" and "wanting" supports the existence of two distinct neural pathways that can independently undergo separate forms of plasticity.

\section{A common neural currency for "wanting"}

Natural rewards such as food, water, and sex all share a common neural substrate. The same is believed to be true for a wide range of addictive substances including alcohol, nicotine, caffeine, barbiturates, benzodiazepines, cannabis, and phencyclidine (Di Chiara \& Imperato, 1988; Wise \& Bozarth, 1987). While these rewards typically all generate pleasure, a vast body of evidence, in both rodents and humans, suggests that the mesolimbic system is preferentially active during exposure to rewards, with the primary consequence being the release of the neurotransmitter dopamine (Balfour, 2015a; Berridge \& Robinson, 1998; Corrigall, Coen, \& Adamson, 1994; Di Chiara \& Imperato, 1988). Although it was long believed that dopamine was the neurotransmitter responsible for pleasure, this has since been disproved, and a large body of evidence suggests that it instead modulates "wanting" (Berridge \& Valenstein, 1991; Peciña, Cagniard, Berridge, Aldridge, \& Zhuang, 2003; Tindell, Berridge, Zhang, Peciña, \& Aldridge, 2005; Wyvell \& Berridge, 2000). In humans, studies show that dopamine levels are more highly correlated with subjective ratings of "wanting" a reward than with pleasure ratings of that same reward (Leyton et al., 2002; Volkow et al., 2002). The mesolimbic dopamine system is thought to be responsible for generating "wanting" and assigning incentive salience to rewards and their cues. This system is comprised of dopaminergic fibers that project from the ventral tegmental area in the midbrain, to limbic and cortical structures such as the nucleus accumbens, ventral pallidum, amygdala, and prefrontal cortex (Di Chiara \& Imperato, 1988; T. E. Robinson \& Berridge, 1993).

Beyond mesolimbic dopamine's role in natural rewards and the self-administration of a wide range of addictive substances, recent evidence also suggests that gambling results in increases in mesolimbic and striatal dopamine release (Joutsa et al., 2012; Linnet et al., 2012; Linnet, Møller, Peterson, Gjedde, \& Doudet, 2011; Zack \& Poulos, 2009). Together this evidence suggests that dopamine may act as a common neural currency for both gambling and substance-use disorder, that may be triggered when exposed to their respective cues, leading to sudden peaks in craving, and ultimately to long-lasting neural changes associated with addiction and relapse.

\section{Cue sensitivity and the sensitization of "wanting"}

Drugs of abuse, like gambling, acquire different degrees of control over thoughts and actions based not only on the effects of drugs themselves or an individual's gambling-related earnings, but also on predispositions of the individual. While alcohol, nicotine, gambling, and other abused substances are rewarding for many individuals, only a subset of users compulsively seek out and engage in these activities. In particular, specific individuals may be more vulnerable to addictive spectrum disorders due to a naturally heightened sensitivity to reward cues (T. E. Robinson, Yager, Cogan, \& Saunders, 2014b; Yager \& Robinson, 2013). These cues can trigger surges in dopamine release that promote intense craving. 
Similarly, repeated exposure to drugs of abuse and gambling can produce intense spikes of mesolimbic dopamine release. Together these repeated peaks of mesolimbic dopamine release lead to brain neuroadaptations, in particular, sensitization of these dopamine-related systems (T. E. Robinson \& Becker, 1986; T. E. Robinson, Jurson, Bennett, \& Bentgen, 1988). Sensitization of mesolimbic dopamine function results in the amplification of the neural mechanisms for incentive salience that transform ordinary levels of cue-triggered "wanting" into excessive levels of urges to take drugs and gamble, and a persistent vulnerability to relapse (Boileau et al., 2014; W. Y. Kim, Cho, Kwak, \& Kim, 2017; Leyton, 2007). This incentive sensitization also produces hyper-reactivity of the mesolimbic dopaminergic system in response to rewardrelated cues, resulting in heightened, intense bouts of cueinduced craving. For example, in animal studies, sensitization increases neuronal firing in VTA-accumbens-pallidal pathways that code incentive salience as well as the behavioral ability of reward cues to trigger frenzied bursts of effort to obtain the reward (Peciña \& Berridge, 2013; Tindell et al., 2005; Wyvell \& Berridge, 2001). Sensitization can also be seen as a greater behavioral response to the drug or enhanced acquisition and escalation of drug self-administration, which accompany brain neural adaptations that underlie amplified "wanting" for the reward (Ferrario et al., 2005; Ferrario \& Robinson, 2007; Vezina, 2004; Vezina et al., 2002). Yet, sensitization does not increase "liking" reactions that reflect the hedonic impact of the reward when it actually arrives (Bartlett et al., 1997).

\section{Cue sensitivity and sensitization in substance abuse}

In humans, studies show that individuals who abuse cocaine or alcohol show abnormally high dopaminergic activity in the ventral striatum and elevated self-reported craving in response to drug-related cues (Heinz et al., 2014; Miedl, Büchel, \& Peters, 2014; Volkow et al., 2006). In smokers, the presentation of smoking-related cues produces enhanced attentional bias towards those cues (Littel, Franken, \& Van Strien, 2009). In fact, greater attentional bias to drug-related cues is not only greater in individuals suffering from substance use, but can actually predict rates of relapse after treatment for numerous drugs, including for nicotine (Jane Powell, Dawkins, West, Powell, \& Pickering, 2010; Waters et al., 2003) and alcohol (W. M. Cox, Hogan, Kristian, \& Race, 2002; W. M. Cox, Pothos, \& Hosier, 2007), suggesting that cue reactivity correlates with drug "wanting." More recently, these behavioral indices of greater attentional bias and incentive salience attributed to drug cues have also been shown to possess several neural correlates that also predict relapse (Janes et al., 2010; Marhe, Luijten, van de Wetering, Smits, \& Franken, 2013). In fact, Franken and colleagues showed that even after 12 months of treatment individuals recovering from a substance-use disorder still displayed heightened cue reactivity, and that exposure to drug cues increased feelings of craving and depression (Franken, de Haan, van der Meer, Haffmans, \& Hendriks, 1999).

Similarly in animals, cue attraction predicts cue-induced reinstatement of nicotine self-administration, while conversely, nicotine administration enhances cue-induced approach behavior (Palmatier, Kellicut, Brianna Sheppard, Brown, \& Robinson, 2014; Versaggi, King, \& Meyer, 2016), an effect that is disrupted by dopamine antagonists (Palmatier et al., 2014). The same is true of alcohol, whereby alcohol-paired cues also trigger cue approach and alcohol-seeking behavior (Krank, 2003; Krank, O'Neill, Squarey, \& Jacob, 2008; Srey, Maddux, \& Chaudhri, 2015; Tomie \& Sharma, 2013). In particular, adolescent alcohol exposure amplifies the incentive value and attraction of reward-predictive cues (Hellberg, Levit, \& Robinson, 2018; Madayag, Stringfield, Reissner, Boettiger, \& Robinson, 2017), and does so through potentiation of dopamine signaling (Spoelder, Tsutsui, Lesscher, Vanderschuren, \& Clark, 2015).

Sensitization caused by repeated drug use has been observed with many drugs of abuse, including alcohol and nicotine (Benwell \& Balfour, 1992; Cadoni \& Di Chiara, 2000; Govind, Vezina, \& Green, 2009; Laviolette \& van der Kooy, 2004). In humans, several reports have provided evidence of sensitization in psychostimulant drug users leading to enhanced drug-seeking, despite showing tolerance to the drug's euphoric effects (Bartlett et al., 1997; Reed et al., 2009; Small et al., 2009). In animals, recent findings have shown that repeated alcohol consumption leading to sensitization results in increased dopaminergic reactivity to alcohol (Didone, Masson, Quoilin, Seutin, \& Quertemont, 2014), and greater behavioral responsivity (Hoshaw \& Lewis, 2001). Similarly, in humans a dissociation has been found between "liking" and "wanting" for alcohol where small doses of alcohol cause spikes in "wanting" yet leave "liking" unaffected (Hobbs, Remington, \& Glautier, 2005; Ostafin, Marlatt, \& TroopGordon, 2010), and heavy drinkers show higher sensitivity to alcohol's stimulating and rewarding effects (A. C. King, Hasin, O'Connor, McNamara, \& Cao, 2016).

For nicotine, animal studies have shown that repeated intermittent injections of nicotine typically cause sensitization or enhancement of the drug's locomotor activating effects (L. K. Baker et al., 2013; Benwell \& Balfour, 1992; Clarke \& Kumar, 1983; Vezina, McGehee, \& Green, 2007). For example, adolescent nicotine treatment predisposes adult rats to develop increased behavioral sensitivity to chronic nicotine treatment and to be more sensitive to the initial effects of nicotine (Bracken, Chambers, Berg, Rodd, \& McBride, 2011). Exposure to nicotine also increases its subsequent self-administration, which is further enhanced by nicotinepaired cues (Neugebauer, Cortright, Sampedro, \& Vezina, 2014). Furthermore, drugs such as nicotine produce increases 
in dopamine transmission but fail to produce any reported "liking" or euphoria in humans, suggesting the absence of any clear relationship between "liking" and the excessive "wanting" that leads to addiction (Balfour, 2015b; Caggiula et al., 2009; Rose, Behm, Westman, \& Johnson, 2000).

\section{Cue sensitivity and sensitization in gambling}

Gambling environments are robustly full of cues, such as flashing lights and sounds (Griffiths, 1993; Noseworthy \& Finlay, 2009; Parke \& Griffiths, 2006), and gamblers have been shown to display greater attentional bias and fixate their gaze for longer on gambling-related cues (Hudson, Olatunji, Gough, Yi, \& Stewart, 2016; McGrath, Meitner, \& Sears, 2018). The cues in the gambling environment in and of themselves have demonstrated the ability to elicit craving and induce urges to gamble (Kushner et al., 2008; Park et al., 2015; Potenza et al., 2003; Wulfert, Maxson, \& Jardin, 2009). For example, individuals playing blackjack in a gambling-like environment reported greater urges to gamble than those in a neutral context (Kushner et al., 2008; McGrath, Dorbeck, \& Barrett, 2013). Interestingly, the effects of cue-induced craving extend beyond the physical casino environment and into the virtual gambling environment. One study analyzed reports of craving in virtual casino environments and found gambling cues to increase subjective reports of craving in recreational gamblers (Park et al., 2015).

Various studies support the notion that cue reactivity is heightened amongst individuals with problematic gambling and gambling behavior (Hønsi, Mentzoni, Molde, \& Pallesen, 2012; Thalemann, Wölfling, \& Grüsser, 2007; Wulfert et al., 2009). For example, individuals with gambling pathology show elevated craving, urges to gamble, and physiological and neurological reactivity to cues associated with gambling (Goudriaan, Yucel, \& van Holst, 2014; van Holst et al., 2012; Wulfert et al., 2009). In particular, problem gamblers appear more sensitive to bias attention towards gambling-related cues and to experience craving after exposure to gambling cues than healthy controls (Goudriaan et al., 2014; van Holst et al., 2012). Similarly, an fMRI study found increased attraction to cues in the gambling setting that required disordered gambling men and healthy controls to view a video of a neutral or gambling scenario. Men with gambling disorder who viewed the gambling scenario showed increased activation in regions previously shown to be involved in emotional and motivational responses (Potenza et al., 2003).

Research has also found that problem gamblers have a sensitized dopaminergic response to gambling-related cues. Studies have correlated striatal dopamine release in problem gamblers with severity of problem gambling (Joutsa et al., 2012) and with self-reported levels of excitement during a gambling task (Linnet et al., 2011). This sensitized "wanting" that is present in problem gamblers might explain their willingness to persist in gambling despite the negative consequences, such as significant financial losses. A study by Linnet and colleagues found that problem gamblers exhibited increased dopamine release in their ventral striatum compared to healthy controls when they lost money in a gambling task, implying that loss has come to generate motivation in problem gamblers (Linnet, Peterson, Doudet, Gjedde, \& Møller, 2010). Additionally, a study by Clark and colleagues found that nearmisses (or almost winning) in a slot machine gambling task recruited areas of the brain that respond to wins. Participants in this study reported that near-misses were significantly less pleasant than full misses, but triggered their urge to play more (L. Clark, Lawrence, Astley-Jones, \& Gray, 2009), illustrating that although problem gamblers do not enjoy losses, they do find losses highly motivating. This provides further evidence for the neural and psychological dissociation of "liking" and "wanting" and an exacerbation of "wanting" in problem gambling.

It is worth mentioning that certain studies instead report a blunted striatal dopamine response to cues in pathological gamblers (Balodis et al., 2012; Miedl, Peters, \& Büchel, 2012). However, it has been suggested that such contradictory reports can be explained by the absence of familiar or relevant gambling cues during laboratory testing (Leyton \& Vezina, 2012), which when present instead produce an exaggerated striatal dopamine response (T. D. L. Steeves et al., 2009). This finding implies that while gambling-related cues take on increased incentive salience, other non-related or unfamiliar cues may become less important or even inhibit motivation (Leyton, 2007, 2014; Leyton \& Vezina, 2012, 2014). What is it then in gambling that enhances the attraction of gambling cues and sensitizes the dopaminergic response?

\section{The role of uncertainty in cue sensitivity and sensitization in gambling}

One of the hallmarks of gambling, and indeed of most games, is the presence of uncertainty (Costikyan, 2013). It is thought that reward uncertainty, like drugs of abuse, may also sensitize neural systems to rewards and reward-related cues (Anselme \& Robinson, 2013; Anselme, Robinson, \& Berridge, 2013; Berridge, 2007; Mascia et al., 2018; M. J. F. Robinson, Anselme, Fischer, \& Berridge, 2014a; Rømer Thomsen et al., 2014). For example, studies in rats suggest that uncertainty pertaining to the probability and magnitude of the reward outcome can cause attribution of additional incentive salience to reward-related cues. Exposure to an uncertain rather than a certain reward schedule (where both the chances of receiving a reward and the magnitude of this reward vary) significantly increases the attention and attraction directed to the reward cue, making uncertain reward-related cues appear more "wanted"(Anselme et al., 2013). Exposure to reward uncertainty even increases the proportion of individuals that 
ascribe incentive value to cues, and further narrows their focus on cues (Hellberg et al., 2018; M. J. F. Robinson, Anselme, Suchomel, \& Berridge, 2015a). The role of uncertainty in attributing excessive incentive value can also be seen in humans. A series of studies by Brevers and colleagues indicate that problem gamblers exhibit attentional bias toward uncertain gambling-related cues as compared to healthy controls, suggesting that these stimuli also take on increased salience in human gamblers and may possess "motivational magnet" properties (Brevers et al., 2014a; Brevers, Koritzky, Bechara, \& Noël, 2014b).

These findings regarding uncertainty are paradoxical since they contradict the idea that the motivational value of a cue should be monotonically related to its predictive value. Under reward uncertainty, when the cue only predicts the reward $50 \%$ of the time, the predictive value of the cue is degraded, yet these findings suggest that it is more attractive and "wanted" more. These results are consistent with the incentive salience theory, however, and highlight the dissociation that can occur between the predictive value of a cue, driven by cue learning (cue-reward association), and the attribution of cue "wanting" (T. E. Robinson \& Flagel, 2009; Zhang, Berridge, Tindell, Smith, \& Aldridge, 2009). Furthermore, cues that predict reward with a large degree of uncertainty are also more likely to acquire incentive salience. For example, distal cues that are on the periphery of our attention are typically ignored under certain and predictable reward conditions, but when reward conditions are unpredictable, these cues attract more attention (M. J. F. Robinson et al., 2014a). The effects of uncertainty also parallel those robustly observed during amphetamine sensitization, suggesting that uncertainty may sensitize craving and reward-seeking comparable to drugs of abuse (M. J. F. Robinson, Anselme, Suchomel, \& Berridge, 2015a). This is likely due to the fact that cues that predict an uncertain reward (50\% probability) produce a greater dopamine signal, originating from the ventral midbrain, during the anticipation of the uncertain outcome (Anselme, 2013; Fiorillo, Tobler, \& Schultz, 2003), and that this dopaminergic signal appears to promote risk-seeking behavior, as evidenced in gambling (Fiorillo, 2011).

One approach for examining the role of uncertainty on risk preference is the rodent gambling task ( $\mathrm{rGT})$, adapted from the Iowa Gambling Task (Bechara, Damasio, Tranel, \& Damasio, 1997; Rivalan, Ahmed, \& Dellu-Hagedorn, 2009; Zeeb, Robbins, \& Winstanley, 2009). It presents animals with the choice of four options (two safe and two risky), each associated with different magnitude and probability of reward, and durations of punishing time-outs. While the majority of animals learn to choose the safe and advantageous options, a small proportion tend to be more risk-preferring, and these risk-preferring animals make more drug-seeking responses and show greater cue-induced incubation of craving after cocaine self-administration (Ferland \& Winstanley, 2016).
Crucially, it appears that repeated exposure to reward uncertainty subsequently increases risk preference on the rGT (Zeeb, Li, Fisher, Zack, \& Fletcher, 2017). Similarly, the introduction of salient cues to winning trials, to what is termed the cued rGT, results in riskier and more disadvantageous choice behavior than when exposed to the uncued task (Barrus \& Winstanley, 2016). Along with evidence that in humans win-associated cues, such as jingles varying in length and size in function of win size, both increase arousal and lead subjects to overestimate their frequency of winning (Dixon et al., 2014), this evidence suggests a strong connection between reward uncertainty, gambling propensity, substance abuse, and cue sensitivity.

In all, research suggests that cues can become powerful instigators of gambling behavior. Therefore, games that are governed by reward uncertainty and contain a large number of cues or a high prevalence of flashing lights and sounds, such as electronic gambling machines, might be particularly capable of eliciting motivated play and sensitizing "wanting" pathways in a manner that promotes excessive attentional bias and risky decision-making. In turn, attentional bias towards gambling cues has been suggested to play a critical role in the transition from recreational to problem gambling (L. D. Grant \& Bowling, 2015; van Holst et al., 2012).

\section{Cue sensitivity and sensitization by stress}

In the human literature, substantial research has supported the notion that individual differences in the sensitivity to cues may also confer risk for anxiety disorders (Bar-Haim, Lamy, Pergamin, Bakermans-Kranenburg, \& van IJzendoorn, 2007; Heeren, Peschard, \& Philippot, 2011; Mogg \& Bradley, 2018; Shackman et al., 2016; Van Bockstaele et al., 2014). However, the majority of this work has examined abnormalities in neural, cognitive, and behavioral reactivity towards threat cues versus neutral cues, or compared to healthy control populations (e.g., Dieterich, Endrass, \& Kathmann, 2017). Within this line of work, uncertainty has emerged as an important moderator of this observed individual difference in sensitivity to threat cues, with individuals with anxiety disorders demonstrating enhanced reactivity to uncertain compared to certain threat cues (Bradford, Kaye, \& Curtin, 2014a; Bradford, Magruder, Korhumel, \& Curtin, 2014b; Grupe \& Nitschke, 2013). Intolerance to uncertainty is a transdiagnostic factor strongly implicated in the maintenance of anxiety disorders, and is associated with greater physiological reactivity, attentional biases, and neural activation to uncertainty and uncertain threat cues (Carleton, 2012; Krain et al., 2006; Mahoney \& McEvoy, 2012; Nelson \& Shankman, 2011; Simmons, Matthews, Paulus, \& Stein, 2008). Notably, individuals with high intolerance to uncertainty display greater neural activity of the insula and amygdala in response to uncertainty (Tanovic, Gee, \& Joormann, 2018). Studies also suggest that 
individuals with high intolerance for uncertainty are susceptible to alcohol use as a form of stress reduction in response to uncertainty, suggesting a possible pathway through which individuals suffering or predisposed to generalized anxiety disorder and exposed to high levels of uncertainty through gambling might be inclined to abuse alcohol as a form of selfmedication (Bradford, Shapiro, \& Curtin, 2013; Hefner, Moberg, Hachiya, \& Curtin, 2013).

However, to date, very few studies have directly examined the distinction and overlap of this neurobiological sensitivity to cues and uncertainty in intense positive and negative valence events. The studies that have examined both reward and threat cue processing do suggest highly overlapping neurobiological and psychological processing abnormalities in anxiety disorders that may generally encompass the attribution of value and recruitment of attention to valenced cues, rather than just threat cues (Gorka, Nelson, Phan, \& Shankman, 2016; Tanovic et al., 2018). In particular, one human study demonstrated that uncertain rewards, similar to threats, result in increased insula responsivity (Gorka et al., 2016). Interestingly, although there are dopaminergic neurons that encode for just positive or negative motivational events, there are more numerous dopaminergic neurons that excite similarly to both threatening and rewarding events (Matsumoto \& Hikosaka, 2009). One animal study has supported this model, with high anxiety animals demonstrating particular vulnerability to attend to reward-related uncertain cues (Hellberg et al., 2018).

Given the uncertainty inherent to games of chance, it follows that individuals at risk for anxiety disorders, due to high levels of intolerance of uncertainty, may be particularly vulnerable to over-attend to uncertainty-related cues and subsequently becoming more motivated and intensely focused on gambling behaviors through incentive sensitization. Both positive and negative valenced cues in gambling, such as those associated with wins and losses, may particularly sensitize reactivity to gambling-related cues in individuals with anxiety disorders.

Furthermore, there is evidence that stress cues similarly elicit craving by inducing anxiety (Coffey, Stasiewicz, Hughes, \& Brimo, 2006; Fox, Bergquist, Hong, \& Sinha, 2007; Sinha \& Li, 2007; Sinha et al., 2009; 2003). Specifically, stress cues significantly increased both alcohol craving and reported anxiety levels in abstinent alcoholdependent individuals (Fox et al., 2007), and this pattern of reactivity was associated with enhanced activation in regions linked to mesolimbic reward processing, including the medial prefrontal, anterior and posterior cingulate, and striatal and posterior insula cortex (Sinha \& $\mathrm{Li}, 2007$ ). These responses to stress cues were on the whole comparable to those induced by alcohol-associated cues (Fox et al., 2007; Sinha et al., 2009; Sinha \& Li, 2007), and support the evidence that the physiological reactivity elicited by stress cues may serve as a powerful catalyst for craving and subsequent relapse (Sinha et al., 2011). In anxiety disorders, such as panic disorder (PD) or post-traumatic stress disorder, interoceptive and physiological sensations serve as particularly potent stress cues, and are known to elicit negative affective states, such as anxiety and even panic attacks. This seems notable, given the relationship between anxiety disorders, such as PD, and the strikingly high rates of co-mordidity and prospective onset of alcohol and tobacco use disorders among these individuals (Zimmermann et al., 2003; Zvolensky, Bernstein, Marshall, \& Feldner, 2006). Interestingly, individuals with PD specifically have been shown to have particularly difficult experiences with withdrawal and high rates of relapse, due to the syndromic sensitivity to these interoceptive arousal cues that characterize withdrawal from tobacco or other substances of abuse (Zvolensky \& Bernstein, 2005; Zvolensky, Stewart, Vujanovic, Gavric, \& Steeves, 2009). These effects have been less well examined within substance use and gambling; however, the mechanism by which somatic cues elicit persistent engagement with nicotine and relapse among these individuals naturally extends to other substance and behavioral addictions.

Stress, similar to drugs of abuse, may also induce neurological changes that enhance dopaminergic activity and the attribution of incentive value to rewards and their cues (Berridge, 2012; T. E. Robinson, Angus, \& Becker, 1985; Yap et al., 2015). Exposure to acute and chronic stressors often results in initial sensitization of the hypothalamic-pituitaryadrenal (HPA) axis, which may then produce hypersensitivity to other stressors. Sensitization can also affect other physiological systems (i.e., plasma catecholamines, brain monoamines), which appears to be long lasting, a finding that may explain the long-term consequences of early-life adversity and traumatic stressors (Belda, Fuentes, Daviu, Nadal, \& Armario, 2015). In particular, there may be critical periods, such as during childhood, in which neural systems are particularly vulnerable to sensitization by stress (Rodrigues, Leão, Carvalho, Almeida, \& Sousa, 2011). There is substantial evidence to support to notion that stressful experiences during early development may sensitize mesolimbic dopamine signaling in neural regions, inducing permanent changes in the neural programming of dopaminergic activity (Rodrigues et al., 2011). These findings align well with the stresssensitization hypothesis of the role of early life adversity in the onset of anxiety disorders, substance use, and gambling disorder (McLaughlin et al., 2010). There is also evidence to suggest that the physiological response to stress, involving elevated corticotropin-releasing factor (CRF), a hormone highly implicated in the stress response, recruits activity in dopaminergic pathways and elevates dopaminergic activity (Berridge, 2010; Cuadra, Zurita, Lacerra, \& Molina, 1999; Dallman, 2010; Peciña, Schulkin, \& Berridge, 2006). In turn, administration of CRF has been shown to elevate the value of 
Pavlovian-associated reward cues (Peciña et al., 2006). Chronic and acute stress may therefore produce similar neural adaptations in the mesolimbic dopamine circuit that are responsible for increased "wanting" of rewards and enhanced cue reactivity. In this vein, stress has been shown to elicit similar neuroadaptations to alcohol and nicotine, increasing the excitatory strength of dopamine neurons in midbrain (e.g., VTA, NAc) in animals (Saal, Dong, Bonci, \& Malenka, 2003). Traumatic events or chronic distressed states, typical of anxiety disorders, may therefore leave individuals more susceptible to the rewarding effects of drugs and gambling and predispose individuals to over-attribute value to drugs and gambling cues. Through these neuroadaptations in the mesolimbic dopamine pathway, dysfunctions in the stress response may heighten the risk for substance use and gambling disorder, and contribute to the high prevalence of comordidity between anxiety, gambling, and substance-use disorders (Fig. 1).

\section{Cross-sensitization as a framework for co-mordidity}

\section{Cross-sensitization: definition}

When experienced together, substances such as nicotine and alcohol, and stress and reward uncertainty might exert a cumulative effect on the mesolimbic reward system, a phenomenon known as cross-sensitization. Cross-sensitization occurs when sensitization to one reward results in an amplified response to another related reward. In the context of drug use, crosssensitization refers to when sensitization to one drug will produce a sensitized response to other drugs (such as between heroin and cocaine) (Antelman, Eichler, Black, \& Kocan, 1980; Cunningham \& Kelley, 1992; Horger, Giles, \& Schenk, 1992; Piazza, Deminiere, le Moal, \& Simon, 1990; T. E. Robinson et al., 1985). In cases of cross-sensitization of "wanting," an individual, as a result of excessively consuming one drug, is rendered hyper-responsive to the motivational effects of other drugs, including ones that may have never been previously consumed. A study by Horger et al. found that rats given nine daily injections of amphetamine or nicotine acquired cocaine self-administration much quicker than control animals (Casey, Benkelfat, Young, \& Leyton, 2006; Horger et al., 1992; Munafò, Mannie, Cowen, Harmer, \& McTavish, 2007), whereas Cortright et al. found that nicotine pretreatment enhances acquisition of amphetamine self-administration, particularly in the presence of nicotine-associated cues (Cortright, Sampedro, Neugebauer, \& Vezina, 2012). Similarly, a study by Cunningham et al. found that rats who were given intraaccumbens treatment of certain opiates (such as morphine) later proved to be sensitized to the behavioral effects of amphetamine (Cunningham \& Kelley, 1992). Together these studies demonstrate that repeated exposure to one drug can render

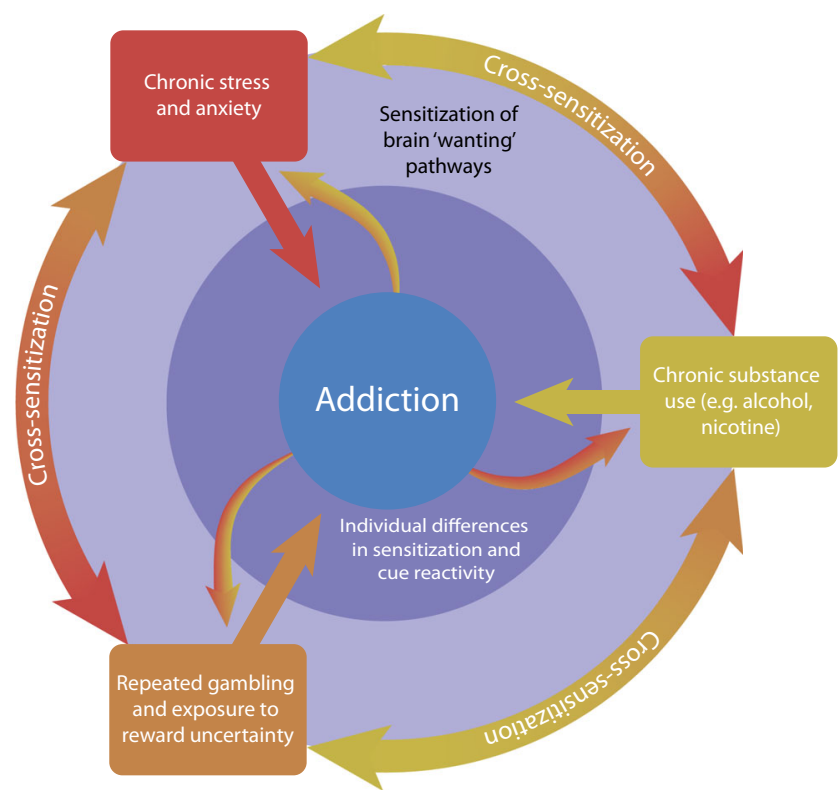

Fig. 1 Anxiety, gambling, and substance use have all been associated with the sensitization of neural pathways involved in motivation and reward (light blue outer ring). These factors may act independently and interact with each other through a process of cross-sensitization (outer ring), conferring significant risk for the development of an addictive spectrum disorder like gambling disorder (center). In turn, the development of an addictive spectrum disorder, whether to a substance or gambling behavior, may increase the risk of developing and subsequent severity of an anxiety, substance use or gambling disorder (outward facing arrows). In addition, beyond chronic exposure, acute encounters with either stress, drugs or gambling and their associated cues may be able to trigger intense bouts of craving and potentially relapse. Finally, individual differences in the propensity to attribute value to reward cues may confound with these factors and put specific individuals at high risk for addiction (dark blue inner ring)

individuals more susceptible to the reinforcing effects of another, and highlight the importance played by contextual cues.

However, cross-sensitization does not only occur between drugs of abuse. Cross-sensitization and the resulting hyperresponsivity of dopaminergic systems also occurs between drugs of abuse and natural rewards (Avena \& Hoebel, 2003) and drugs of abuse and stress (at both behavioral and physiological levels) (Cruz, Marin, Leão, \& Planeta, 2011; GarciaKeller et al., 2013; Piazza et al., 1990). There is also evidence for cross-sensitization between drugs of abuse and gambling (Boileau et al., 2014; Mascia et al., 2018; Singer, ScottRailton, \& Vezina, 2012; Zack, Featherstone, Mathewson, \& Fletcher, 2014; Zeeb et al., 2017), and between gambling and stress (C. L. Green et al., 2017).

\section{Cross-sensitization between drugs and gambling}

The most compelling evidence for neural sensitization of dopamine release and resulting cross-sensitization with gambling comes from Parkinson patients who develop dopamine dysregulation syndrome (DDS). DDS occurs in a small proportion of 
Parkinson's patients being treated with dopamine agonist medication (Dodd et al., 2005; Evans, Lawrence, Cresswell, Katzenschlager, \& Lees, 2010; Evans et al., 2006). It typically leads to compulsive use of their dopaminergic drug medications, with increased reports of drug "wanting" but not drug "liking." It is also accompanied by increased dopamine release in the ventral striatum especially in the combined presence of cues and the dopamine-stimulating drug. Crucially, it is frequently accompanied by the development of pathological gambling, hypersexuality, food bingeing, and punding (a form of complex behavioral stereotypy), suggesting that incentive sensitization of their dopamine-stimulating medication produces cross-sensitization to several other rewards including gambling. Interestingly, in many of these patients, discontinuation of their dopaminergic medication resolved their pathological gambling (Dodd et al., 2005).

There is also direct evidence for cross-sensitization of the dopaminergic system under gambling-like conditions in animals (Mascia et al., 2018; Singer et al., 2012; Zack et al., 2014; Zeeb et al., 2017). Uncertainty causes cross-sensitization of the dopaminergic system, as seen by increased reactivity to a single dose of amphetamine, in the same way that repeated exposure to drugs of abuse sensitizes this system. Zack and colleagues found that rats exposed to maximally uncertain conditions showed the greatest locomotor response to an amphetamine challenge (Zack et al., 2014). In a similar study, Singer and his collaborators found that rats trained to press a lever for reward on a variable schedule showed a greater locomotor response to amphetamine than those who were rewarded on a fixed schedule (Singer et al., 2012). Using a similar approach, Mascia and her colleagues found that repeated exposure to uncertainty resulted in self-administration of more amphetamine and a greater dopaminergic response to amphetamine (Mascia et al., 2018).

Cross-sensitization of dopaminergic systems from gambling has also been observed in humans. Boileau and colleagues found that problem gamblers have increased dopamine release in their dorsal striatum in response to amphetamine in comparison with healthy controls (Boileau et al., 2014). Conversely, a study by Barrett and colleagues examined the effect of co-administration of alcohol and nicotine in regular video lottery terminal gamblers. Their results showed that while administration of alcohol increased cigarette craving and "wanting" to consume more alcohol, it also increased the urge to gamble, whereas nicotine increased average wagers. This suggests that both alcohol and nicotine increased the incentive value and propensity to gamble but through separate processes (Barrett, Collins, \& Stewart, 2015).

Together these results suggest that exposure to reward uncertainty and gambling can increase sensitivity to drugs of abuse, which in turn can increase the incentive value associated to gambling and its cues, and possibly promote the transition from casual recreational gambling to compulsive gambling.

\section{Cross-sensitization between drugs and stress}

There is a long history of evidence suggesting that prior exposure to chronic or acute stress predisposes individuals to substance use and abuse. In particular, evidence suggests that final maturation of behavior, dopamine systems, and HPA axis occurs during adolescence, suggesting that individuals experiencing stressful events during early life and adolescence are particularly prone to develop cross-sensitization to drugs of abuse (Burke \& Miczek, 2014; Rodrigues et al., 2011). For example, in one study, chronically stressed animals displayed a sensitized response to the effects of acute cocaine administration, increased self-administration of cocaine, and demonstrated increased dopamine release in the nucleus accumbens (Holly, Shimamoto, DeBold, \& Miczek, 2012). A study by Zago and colleagues demonstrated that the co-occurrence of repeated stress alongside chronic nicotine administration resulted in behavioral sensitization, particularly in adolescent animals (Zago et al., 2012). Some studies have reported sex differences in cross-sensitization, where early life stress enhanced nicotine sensitization in female rats, yet rendered males more sensitive to further stress (McCormick, Robarts, Gleason, \& Kelsey, 2004). Repeated stress during adolescence has also been shown to increase the incentive value and attraction to contexts previously paired with either nicotine or alcohol, even at lower doses (Brielmaier, McDonald, \& Smith, 2012; Song et al., 2007). In mice, chronic stress during adolescence has also been shown to increase alcohol preference and overall alcohol consumption in adulthood (Chester, Barrenha, Hughes, \& Keuneke, 2008; Lopez, DoremusFitzwater, \& Becker, 2011). Similar findings have also been reported in humans, where adverse childhood experiences were associated with increased likelihood of alcohol use during adolescence and of alcohol abuse as an adult (Dube, Anda, Felitti, Edwards, \& Croft, 2002; Dube et al., 2006; Enoch, 2011). Together these findings strongly suggest a role for stress, particularly during early life and adolescence, in sensitizing reward systems responsible for the attribution of drug and cue "wanting," thus placing individuals at greater risk for substance-use disorders, such as commonly observed in alcohol and nicotine dependence. However, the relationship between drugs and stress is not unidirectional. Recent human studies have shown that exposure to only three doses of amphetamine can cause cross-sensitization to stress, resulting in an increased cortisol response to stress and greater striatal dopamine release (Booij et al., 2016). Such findings are problematic when one considers that beyond the impact of stress on the initial response and consumption to drugs of abuse, stressful life events can also act as powerful triggers of drug cravings and relapse. For example, many human and animal studies have shown that exposure to acute and chronic stress following abstinence increases the likelihood of relapse to both alcohol and nicotine (Breese et al., 2005; Buczek, Lê, 
Wang, Stewart, \& Shaham, 1999; Lê et al., 1998; Mantsch, Baker, Funk, Lê, \& Shaham, 2016; Matheny \& Weatherman, 1998; Perkins \& Grobe, 1992). Taken together these findings suggest the potential existence of a vicious cycle whereby acute or chronic stress enhances "wanting" for drugs and their cues. This in turn may serve to increase stress through financial, social, and other impairments caused by escalating drug use. In addition, attempts at abstinence may precipitate withdrawal, which can promote further anxiety, resulting in enhanced dopaminergic reactivity to drugs and their cues, therefore placing individuals at greater risk for stress-induced relapse (Fig. 1).

\section{Cross-sensitization between gambling and stress}

Similar to drugs of abuse, there is evidence suggesting that stress may render individuals more vulnerable to gambling behavior and associated reward cues (Biback \& Zack, 2015). A recent study by Green and colleagues investigated the relationship between post-traumatic stress symptoms and gambling problems. Their findings suggest that pathological gamblers displayed greater post-traumatic stress symptoms, specifically they demonstrated enhanced severity of associated physiological arousal. The degree of post-traumatic stress symptomatology correlated with greater gambling severity, suggesting a strong relationship between experience of stressful events and gambling problems (C. L. Green et al., 2017) and highlighting enhanced physiological reactivity as a potential contributing factor to this association. In a pilot study, Elman and colleagues attempted to examine whether pathological gamblers were more sensitive to stress by injecting them with yohimbine, an alpha-2 adrenoceptor antagonist that elicits stress-like physiological and psychological effects in both humans and in laboratory animals. They found that in pathological gamblers, yohimbine produced greater reactivity in the left amygdala and tended to elicit greater subjective stress ratings than in healthy controls (Elman et al., 2012). Additional studies by the same group also found that psychosocial stress strongly correlated with gambling urges, particularly in women (Elman, Tschibelu, \& Borsook, 2010; Tschibelu \& Elman, 2011). In contrast, a recent study examining risky decision-making more broadly, found that cortisol led to a striking increase in risk-taking in men, whereas it had no effect on risk-taking behavior in women (Kluen, Agorastos, Wiedemann, \& Schwabe, 2017). In animals, studies using the rodent Gambling Task demonstrated that injections of corticosterone prevented animals from improving their decision-making and avoiding disadvantageous options (Koot, Baars, Hesseling, van den Bos, \& Joëls, 2013). Taken together these results highlight a link between gambling propensity and stress; however, further studies are needed to examine whether acute stress produces greater dopaminergic responses in individuals suffering from gambling disorder.
In addition, while evidence appears to suggest that stress might be a direct constituent of the response to uncertainty, chronic stress also appears to place individuals at greater risk of gambling pathology. The direction of the relationship between gambling and stress may therefore be bi-directional, but further research is needed for it to be fully elucidated.

\section{Long-lasting neuroadaptations}

Possibly the most concerning finding regarding the impact of incentive sensitization and cross-sensitization on co-mordidity between stress, drugs of abuse, and gambling is that the neural changes that underlie sensitization, and thus cross-sensitization, appear to be long-lasting. This would explain why sensitization to stress during early life and adolescence can still have an impact on reward sensitivity to drugs of abuse like nicotine and alcohol and gambling during adulthood. A study by Paulson and colleagues showed that when rats were pretreated with amphetamine, they exhibited sensitization an entire year after the pretreatment was discontinued (Paulson, Camp, \& Robinson, 1991). Likewise, other studies have reported that mice demonstrate behavioral or psychomotor sensitization, in the form of increased locomotor activity, up to 3 months after cocaine exposure (Shuster, Yu, \& Bates, 1977) and up to 8 months after morphine exposure (Shuster, Webster, \& Yu, 1975), while monkeys still display a sensitized response to amphetamine even 2 years post-treatment (Castner \& Goldman-Rakic, 1999). In humans, evidence suggests that exposure to only four doses of amphetamine produced a sensitized dopaminergic response when tested up to 1 year later (Boileau et al., 2006). These results might explain why recent evidence suggests that exposure to early life adversity in rats increases reward and cue "wanting," and potentiates the expression of addiction-related traits in adulthood (Hynes et al., 2017). Studies like these confirm that the neuroadaptations seen in the brain that underlie incentive and dopaminergic sensitization are long-lasting. In fact, these neuroadaptations are believed to persist even long after an individual has undergone recovery from substance use or gambling disorder. This pervasive sensitization of the mesolimbic dopamine system would explain why bouts of craving can occur even years later and why stress remains such a potent trigger of relapse.

\section{Susceptibility to sensitization}

It is important to note that incentive sensitization does not affect everyone equally. Sensitization is a complex phenomenon that is influenced by the quantity, timing, and spacing with which a reward or stress is encountered, along with the context in which it is experienced. These factors interact with individual features of the person, including genes, sex, hormonal status, etc. The phenomenon of sensitization displays a 
tremendous amount of individual variation, with some individuals developing rapid and robust sensitization in contrast to others who sensitize very little, if at all. Some of this can be explained by the fact that individuals differ in their patterns of drug-taking (Allain, Minogianis, Roberts, \& Samaha, 2015). To date, it has been shown in animals that there are genetic differences in the propensity of individual brains to undergo sensitization, and in the functioning of the mesolimbic dopamine system (Dietz, Tapocik, Gaval-Cruz, \& Kabbaj, 2005; Phillips, 1997). There is also evidence suggesting that the genetic variation in acute responsiveness to drugs is different to that responsible for differences in sensitization (EisenerDorman, Grabowski-Boase, \& Tarantino, 2011; Phillips, Huson, \& McKinnon, 1998; Phillips, Huson, Gwiazdon, Kasch, \& Shen, 1995). Nonetheless, most animals and likely humans do show some degree of psychomotor sensitization, although few may still reach the levels sufficient to trigger compulsive drug-seeking and taking. However, for those who do become sensitized, mesolimbic interactions with corticolimbic circuitry focus excessive desire specifically on that target of addiction, resulting in surges of enhanced "wanting" of the addictive target upon encountering related cues or vivid imagery. This heightened "wanting" in response to cues in turn leads to sudden and almost uncontrollable bouts of cuetriggered craving and excessive control of behavior by reward-related cues.

\section{Concluding remarks}

In a gambling setting, cues associated with gambling machines, cigarette smoking, and alcohol use may work synergistically to drive motivation, and the cross-sensitization of reward pathways caused by these factors might accelerate and worsen the pathology of gambling disorder. Here, we reviewed the literature suggesting a mechanistic interplay between stress/anxiety, alcohol and nicotine use, and gambling disorder, and provided a framework to suggest that comordidity and cue reactivity may powerfully moderate one's vulnerability as it pertains to disordered gambling behavior.

To date, a few of the most common options for gambling disorder treatment include group psychotherapy, conjoint marital therapy, psychoanalysis, brief therapy, behavioral counseling, cognitive restructuring, hypnotherapy, and pharmacological and physiological treatments. Of these options, the cognitive and behavioral treatments, which include problem solving, social skills training, and relapse prevention, seem to provide the most promise (Petry \& Armentano, 1999). However, there is no standard intervention for gambling disorder, and long-term rates of abstinence are alarmingly low. In fact, an analysis of various treatment outcomes revealed that $50 \%$ of individuals remain abstinent at 6 months post-gambling involvement, approximately $29 \%$ remain abstinent after 1 year, and only $15 \%$ are abstinent after 2 years (Stinchfield \& Winters, 2001). Gamblers Anonymous, the most popular form of intervention, has an alarmingly low abstinence rate, with only $8 \%$ of patients remaining abstinent after 1 year of treatment (Petry \& Armentano, 1999). Studies of epidemiology and co-mordidity demonstrate a large degree of variation within the disordered gambling population, and gambling disorder treatments fail to successfully address comordidity, cultural influences, and socio-demographic differences within the gambling population.

To better understand the mechanisms that contribute to disordered gambling behavior, future studies will need to address all the factors that contribute to the development and maintenance of gambling behavior and how they interact. This includes co-mordidity across substance-use disorders, particularly alcohol and nicotine use, and anxiety disorders. Crucially, further research is needed to better understand the phenomenon of cross-sensitization between these different disorders in a hope to develop treatments that regulate its effects on cue reactivity and possibly reverse some of the neural adaptations that underlie its development. Studying the combined effects of gambling disorder, substance abuse, and anxiety diagnoses is a crucial next step in understanding the underpinnings of gambling disorder and developing effective treatments.

\section{References}

Afifi, T. O., Nicholson, R., Martins, S. S., \& Sareen, J. (2016). A Longitudinal Study of the Temporal Relation Between Problem Gambling and Mental and Substance Use Disorders Among Young Adults. The Canadian Journal of Psychiatry, 61(2), 102111. https://doi.org/10.1177/0706743715625950

Allain, F., Minogianis, E.-A., Roberts, D. C. S., \& Samaha, A.-N. (2015). How fast and how often: The pharmacokinetics of drug use are decisive in addiction. Neuroscience and Biobehavioral Reviews, 56, 166-179. https://doi.org/10.1016/j.neubiorev.2015.06.012

American Psychiatric Association. (2013). American Psychiatric Association: Diagnostic and Statistical Manual of Mental Disorders, Fifth Edition (DSM-5®). (A. P. Association, Ed.). Arlington: American Psychiatric Association.

Anselme, P. (2013). Dopamine, motivation, and the evolutionary significance of gambling-like behaviour. Behavioural Brain Research, 256C, 1-4. https://doi.org/10.1016/j.bbr.2013.07.039

Anselme, P., \& Robinson, M. J. F. (2013). What motivates gambling behavior? Insight into dopamine's role. Frontiers in Behavioral Neuroscience, 7, 182. https://doi.org/10.3389/fnbeh.2013.00182

Anselme, P., Robinson, M. J. F., \& Berridge, K. C. (2013). Reward uncertainty enhances incentive salience attribution as sign-tracking. Behavioural Brain Research, 238, 53-61. https://doi.org/10.1016/j. bbr.2012.10.006

Antelman, S. M., Eichler, A. J., Black, C. A., \& Kocan, D. (1980). Interchangeability of stress and amphetamine in sensitization. Science, 207(4428), 329-331.

Avena, N. M., \& Hoebel, B. G. (2003). A diet promoting sugar dependency causes behavioral cross-sensitization to a low dose of amphetamine. Neuroscience, 122(1), 17-20. 
Baker, L. K., Mao, D., Chi, H., Govind, A. P., Vallejo, Y. F., Iacoviello, M., et al. (2013). Intermittent nicotine exposure upregulates nAChRs in VTA dopamine neurons and sensitises locomotor responding to the drug. European Journal of Neuroscience, 37(6), 1004-1011. https://doi.org/10.1111/ejn.12114

Balfour, D. J. K. (2015a). The role of mesoaccumbens dopamine in nicotine dependence. (D. J. K. Balfour \& M. R. Munafò, Eds.)The Neuropharmacology of Nicotine Dependence (Vol. 24, pp. 1-172). Cham: Current topics in behavioral neurosciences. doi:10.1007/978$3-319-13482-63$

Balfour, D. J. K. (2015b). The role of mesoaccumbens dopamine in nicotine dependence. Current Topics in Behavioral Neurosciences, 24(Chapter 3), 55-98. https://doi.org/10.1007/978-3-319-13482-6 3

Balodis, I. M., Kober, H., Worhunsky, P. D., Stevens, M. C., Pearlson, G. D., \& Potenza, M. N. (2012). Diminished frontostriatal activity during processing of monetary rewards and losses in pathological gambling. Biological Psychiatry, 71(8), 749-757. https://doi.org/10. 1016/j.biopsych.2012.01.006

Bar-Haim, Y., Lamy, D., Pergamin, L., Bakermans-Kranenburg, M. J., \& van IJzendoorn, M. H. (2007). Threat-related attentional bias in anxious and nonanxious individuals: A meta-analytic study. Psychological Bulletin, 133(1), 1-24. https://doi.org/10.1037/ 0033-2909.133.1.1

Barrett, S. P., Collins, P., \& Stewart, S. H. (2015). The acute effects of tobacco smoking and alcohol consumption on video-lottery terminal gambling. Pharmacology, Biochemistry, and Behavior, 130(C), 34 39. https://doi.org/10.1016/j.pbb.2014.12.015

Barrus, M. M., \& Winstanley, C. A. (2016). Dopamine D3 Receptors Modulate the Ability of Win-Paired Cues to Increase Risky Choice in a Rat Gambling Task. Journal of Neuroscience, 36(3), 785-794. https://doi.org/10.1523/JNEUROSCI.2225-15.2016

Bartlett, E., Hallin, A., Chapman, B., \& Angrist, B. (1997). Selective sensitization to the psychosis-inducing effects of cocaine: a possible marker for addiction relapse vulnerability? Neuropsychopharmacology, 16(1), 77-82. https://doi.org/10.1016/S0893-133X(96)00164-9

Bechara, A., Damasio, H., Tranel, D., \& Damasio, A. R. (1997). Deciding advantageously before knowing the advantageous strategy. Science, 275(5304), 1293-1295.

Belda, X., Fuentes, S., Daviu, N., Nadal, R., \& Armario, A. (2015). Stress-induced sensitization: the hypothalamic-pituitary-adrenal axis and beyond. Stress, 18(3), 269-279. https://doi.org/10.3109/ 10253890.2015 .1067678

Benowitz, N. L. (1996). Pharmacology of nicotine: addiction and therapeutics. Annual Review of Pharmacology and Toxicology, 36(1), 597-613. https://doi.org/10.1146/annurev.pa.36.040196.003121

Benwell, M. E., \& Balfour, D. J. (1992). The effects of acute and repeated nicotine treatment on nucleus accumbens dopamine and locomotor activity. British Journal of Pharmacology, 105(4), 849-856.

Bergamini, A., Turrina, C., Bettini, F., Toccagni, A., Valsecchi, P., Sacchetti, E., \& Vita, A. (2018). At-risk gambling in patients with severe mental illness: Prevalence and associated features. Journal of Behavioral Addictions, 7(2), 348-354. https://doi.org/10.1556/ 2006.7.2018.47

Berridge, K. C. (2007). The debate over dopamine's role in reward: the case for incentive salience. Psychopharmacology, 191(3), 391-431. https://doi.org/10.1007/s00213-006-0578-x

Berridge, K. C. (2010). Incentive Motivation and Incentive Salience (pp. $1-8)$. Elsevier.

Berridge, K. C. (2012). From prediction error to incentive salience: mesolimbic computation of reward motivation. European Journal of Neuroscience, 35(7), 1124-1143. https://doi.org/10.1111/j.14609568.2012.07990.x

Berridge, K. C., \& Robinson, T. E. (1998). What is the role of dopamine in reward: hedonic impact, reward learning, or incentive salience? Brain Research Reviews, 28(3), 309-369.
Berridge, K. C., \& Robinson, T. E. (2003). Parsing reward. Trends in Neurosciences, 26(9), 507-513. https://doi.org/10.1016/S01662236(03)00233-9

Berridge, K. C., Robinson, T. E., \& Aldridge, J. W. (2009). Dissecting components of reward: 'liking', "wanting," and learning. Current Opinion in Pharmacology, 9(1), 65-73. https://doi.org/10.1016/j. coph.2008.12.014

Berridge, K. C., \& Valenstein, E. S. (1991). What psychological process mediates feeding evoked by electrical stimulation of the lateral hypothalamus? Behavioral Neuroscience, 105(1), 3-14.

Biback, C., \& Zack, M. (2015). The Relationship Between Stress and Motivation in Pathological Gambling: a Focused Review and Analysis. Current Addiction Reports, 2(3), 230-239. https://doi. org/10.1007/s40429-015-0064-9

Blanco, C., Hanania, J., Petry, N. M., Wall, M. M., Wang, S., Jin, C. J., \& Kendler, K. S. (2015). Towards a comprehensive developmental model of pathological gambling. Addiction, 110(8), 1340-1351. https://doi.org/10.1111/add.12946

Blanco, C., Hasin, D. S., Petry, N., Stinson, F. S., \& Grant, B. F. (2006). Sex differences in subclinical and DSM-IV pathological gambling: results from the National Epidemiologic Survey on Alcohol and Related Conditions. Psychological Medicine, 36(7), 943-953. https://doi.org/10.1017/S0033291706007410

Blaszczynski, A., \& Nower, L. (2002). A pathways model of problem and pathological gambling. Addiction, 97(5), 487-499. https://doi.org/ 10.1046/j.1360-0443.2002.00015.x

Boileau, I., Dagher, A., Leyton, M., Gunn, R. N., Baker, G. B., Diksic, M., \& Benkelfat, C. (2006). Modeling sensitization to stimulants in humans: an [11C]raclopride/positron emission tomography study in healthy men. Archives of General Psychiatry, 63(12), 1386-1395. https://doi.org/10.1001/archpsyc.63.12.1386

Boileau, I., Payer, D., Chugani, B., Lobo, D. S. S., Houle, S., Wilson, A. A., et al. (2014). In vivo evidence for greater amphetamine-induced dopamine release in pathological gambling: a positron emission tomography study with [(11)C]-(+)-PHNO. Nature Publishing Group, 19(12), 1305-1313. https://doi.org/10.1038/mp.2013.163

Booij, L., Welfeld, K., Leyton, M., Dagher, A., Boileau, I., Sibon, I., et al. (2016). Dopamine cross-sensitization between psychostimulant drugs and stress in healthy male volunteers. Translational Psychiatry, 6(2), e740. https://doi.org/10.1038/tp.2016.6

Bracken, A. L., Chambers, R. A., Berg, S. A., Rodd, Z. A., \& McBride, W. J. (2011). Nicotine exposure during adolescence enhances behavioral sensitivity to nicotine during adulthood in Wistar rats. Pharmacology, Biochemistry, and Behavior, 99(1), 87-93. https:// doi.org/10.1016/j.pbb.2011.04.008

Bradford, D. E., Kaye, J. T., \& Curtin, J. J. (2014a). Not just noise: individual differences in general startle reactivity predict startle response to uncertain and certain threat. Psychophysiology, 51(5), 407-411. https://doi.org/10.1111/psyp.12193

Bradford, D. E., Magruder, K. P., Korhumel, R. A., \& Curtin, J. J. (2014b). Using the threat probability task to assess anxiety and fear during uncertain and certain threat. Journal of Visualized Experiments : JoVE, (91), 51905-e51905. https://doi.org/10.3791/ 51905

Bradford, D. E., Shapiro, B. L., \& Curtin, J. J. (2013). How Bad Could It Be? Alcohol Dampens Stress Responses to Threat of Uncertain Intensity. Psychological Science, 24(12), 2541-2549. https://doi. org/10.1177/0956797613499923

Breese, G. R., Chu, K., Dayas, C. V., Funk, D., Knapp, D. J., Koob, G. F., et al. (2005). Stress enhancement of craving during sobriety: a risk for relapse. (Vol. 29, pp. 185-195). Presented at the Alcoholism, clinical and experimental research.

Brevers, D., Bechara, A., Hermoye, L., Divano, L., Kornreich, C., Verbanck, P., \& Noël, X. (2014a). Comfort for uncertainty in pathological gamblers: A fMRI study. Behavioural Brain Research, 278C, 262-270. https://doi.org/10.1016/j.bbr.2014.09.026 
Brevers, D., Koritzky, G., Bechara, A., \& Noël, X. (2014b). Cognitive processes underlying impaired decision-making under uncertainty in gambling disorder. Addictive Behaviors, 39(10), 1533-1536. https://doi.org/10.1016/j.addbeh.2014.06.004

Brielmaier, J., McDonald, C. G., \& Smith, R. F. (2012). Effects of acute stress on acquisition of nicotine conditioned place preference in adolescent rats: a role for corticotropin-releasing factor 1 receptors. Psychopharmacology, 219(1), 73-82. https://doi.org/10.1007/ s00213-011-2378-1

Buczek, Y., Lê, A. D., Wang, A., Stewart, J., \& Shaham, Y. (1999). Stress reinstates nicotine seeking but not sucrose solution seeking in rats. Psychopharmacology, 144(2), 183-188.

Burke, A. R., \& Miczek, K. A. (2014). Stress in adolescence and drugs of abuse in rodent models: role of dopamine, CRF, and HPA axis. Psychopharmacology, 231(8), 1557-1580. https://doi.org/10.1007/ s00213-013-3369-1

Cadoni, C., \& Di Chiara, G. (2000). Differential changes in accumbens shell and core dopamine in behavioral sensitization to nicotine. European Journal of Pharmacology, 387(3), R23-5. https://doi. org/10.1016/S0014-2999(99)00843-2

Caggiula, A. R., Donny, E. C., Palmatier, M. I., Liu, X., Chaudhri, N., \& Sved, A. F. (2009). The role of nicotine in smoking: a dualreinforcement model. Nebraska Symposium on Motivation. Nebraska Symposium on Motivation, 55, 91-109.

Carleton, R. N. (2012). The intolerance of uncertainty construct in the context of anxiety disorders: theoretical and practical perspectives. Expert Review of Neurotherapeutics, 12(8), 937-947. https://doi. org/10.1586/ern.12.82

Casey, K. F., Benkelfat, C., Young, S. N., \& Leyton, M. (2006). Lack of effect of acute dopamine precursor depletion in nicotine-dependent smokers. European Neuropsychopharmacology, 16(7), 512-520. https://doi.org/10.1016/j.euroneuro.2006.02.002

Castner, S. A., \& Goldman-Rakic, P. S. (1999). Long-lasting psychotomimetic consequences of repeated low-dose amphetamine exposure in rhesus monkeys. Neuropsychopharmacology, 20(1), 10-28. https://doi.org/10.1016/S0893-133X(98)00050-5

Chester, J. A., Barrenha, G. D., Hughes, M. L., \& Keuneke, K. J. (2008). Age- and Sex-Dependent Effects of Footshock Stress on Subsequent Alcohol Drinking and Acoustic Startle Behavior in Mice Selectively Bred for High-Alcohol Preference. Alcoholism, Clinical and Experimental Research, 32(10), 1782-1794. https://doi.org/10. 1111/j.1530-0277.2008.00763.x

Chou, K.-L., \& Afifi, T. O. (2011). Disordered (Pathologic or Problem) Gambling and Axis I Psychiatric Disorders: Results From the National Epidemiologic Survey on Alcohol and Related Conditions. American Journal of Epidemiology, 173(11), 12891297. https://doi.org/10.1093/aje/kwr017

Clark, L., Lawrence, A. J., Astley-Jones, F., \& Gray, N. (2009). Gambling Near-Misses Enhance Motivation to Gamble and Recruit WinRelated Brain Circuitry. Neuron, 61(3), 481-490. https://doi.org/ 10.1016/j.neuron.2008.12.031

Clarke, P. B. S., \& Kumar, R. (1983). The effects of nicotine on locomotor activity in non-tolerant and tolerant rats. British Journal of Pharmacology, 78(2), 329-337. https://doi.org/10.1111/j.14765381.1983.tb09398.x

Coffey, S. F., Stasiewicz, P. R., Hughes, P. M., \& Brimo, M. L. (2006). Trauma-focused imaginal exposure for individuals with co-mordid posttraumatic stress disorder and alcohol dependence: Revealing mechanisms of alcohol craving in a cue reactivity paradigm. Psychology of Addictive Behaviors, 20(4), 425-435. https://doi. org/10.1037/0893-164X.20.4.425

Conway, K. P., Compton, W., Stinson, F. S., \& Grant, B. F. (2006). Lifetime co-mordidity of DSM-IV mood and anxiety disorders and specific drug use disorders: results from the National Epidemiologic Survey on Alcohol and Related Conditions. The Journal of Clinical Psychiatry, 67(2), 247-257.
Corrigall, W. A., Coen, K. M., \& Adamson, K. L. (1994). Selfadministered nicotine activates the mesolimbic dopamine system through the ventral tegmental area. Brain Research, 653(1), 278284. https://doi.org/10.1016/0006-8993(94)90401-4

Cortright, J. J., Sampedro, G. R., Neugebauer, N. M., \& Vezina, P. (2012). Previous Exposure to Nicotine Enhances the Incentive Motivational Effects of Amphetamine via Nicotine-Associated Contextual Stimuli. Neuropsychopharmacology, 37(10), 2277. https://doi.org/ 10.1038/npp.2012.80

Costikyan, G. (2013). Uncertainty in Games. Cambridge: MIT Press.

Cox, W. M., Hogan, L. M., Kristian, M. R., \& Race, J. H. (2002). Alcohol attentional bias as a predictor of alcohol abusers' treatment outcome. Drug and Alcohol Dependence, 68(3), 237-243. https://doi.org/10. 1016/S0376-8716(02)00219-3

Cox, W. M., Pothos, E. M., \& Hosier, S. G. (2007). Cognitivemotivational predictors of excessive drinkers' success in changing. Psychopharmacology, 192(4), 499-510. https://doi.org/10.1007/ s00213-007-0736-9

Crockford, D. N., \& el-Guebaly, N. (1998). Psychiatric co-mordidity in pathological gambling: a critical review. The Canadian Journal of Psychiatry, 43(1), 43-50. https://doi.org/10.1177/ 070674379804300104

Cruz, F. C., Marin, M. T., Leão, R. M., \& Planeta, C. S. (2011). Stressinduced cross-sensitization to amphetamine is related to changes in the dopaminergic system. Journal of Neural Transmission, 119(4), 415-424. https://doi.org/10.1007/s00702-011-0720-8

Cuadra, G., Zurita, A., Lacerra, C., \& Molina, V. (1999). Chronic stress sensitizes frontal cortex dopamine release in response to a subsequent novel stressor: reversal by naloxone. Brain Research Bulletin, 48(3), 303-308. https://doi.org/10.1016/S0361-9230(98)00179-8

Cunningham, S. T., \& Kelley, A. E. (1992). Evidence for opiatedopamine cross-sensitization in nucleus accumbens: studies of conditioned reward. Brain Research Bulletin, 29(5), 675-680.

Cunningham-Williams, R. M., Grucza, R. A., Cottler, L. B., Womack, S. B., Books, S. J., Przybeck, T. R., et al. (2005). Prevalence and predictors of pathological gambling: results from the St. Louis personality, health and lifestyle (SLPHL) study. Journal of Psychiatric Research, 39(4), 377-390. https://doi.org/10.1016/j.jpsychires. 2004.09.002

Dallman, M. F. (2010). Stress-induced obesity and the emotional nervous system. Trends in Endocrinology and Metabolism: TEM, 21(3), 159-165. https://doi.org/10.1016/j.tem.2009.10.004

Desai, R. A., \& Potenza, M. N. (2008). Gender differences in the associations between past-year gambling problems and psychiatric disorders. Social Psychiatry and Psychiatric Epidemiology, 43(3), 173183. https://doi.org/10.1007/s00127-007-0283-z

Di Chiara, G., \& Imperato, A. (1988). Drugs abused by humans preferentially increase synaptic dopamine concentrations in the mesolimbic system of freely moving rats. Proceedings of the National Academy of Sciences, 85(14), 5274-5278.

Di Nicola, M., Tedeschi, D., De Risio, L., Pettorruso, M., Martinotti, G., Ruggeri, F., et al. (2015). Co-occurrence of alcohol use disorder and behavioral addictions: relevance of impulsivity and craving. Drug and Alcohol Dependence, 148, 118-125. https://doi.org/10.1016/j. drugalcdep.2014.12.028

Didone, V., Masson, S., Quoilin, C., Seutin, V., \& Quertemont, E. (2014). Correlation between ethanol behavioral sensitization and midbrain dopamine neuron reactivity to ethanol. Addiction Biology, 21(2), 387-396. https://doi.org/10.1111/adb.12216

Dieterich, R., Endrass, T., \& Kathmann, N. (2017). Uncertainty increases neural indices of attention in obsessive-compulsive disorder. Depression and Anxiety, 34(11), 1018-1028. https://doi.org/10. 1002/da.22655

Dietz, D. M., Tapocik, J., Gaval-Cruz, M., \& Kabbaj, M. (2005). Dopamine transporter, but not tyrosine hydroxylase, may be implicated in determining individual differences in behavioral 
sensitization to amphetamine. Physiology \& Behavior, 86(3), 347355. https://doi.org/10.1016/j.physbeh.2005.08.005

Dixon, M. J., Graydon, C., Harrigan, K. A., Wojtowicz, L., Siu, V., \& Fugelsang, J. A. (2014). The allure of multi-line games in modern slot machines. Addiction, 109(11), 1920-1928. https://doi.org/10. 1111/add.12675

Dodd, M. L., Klos, K. J., Bower, J. H., Geda, Y. E., Josephs, K. A., \& Ahlskog, J. E. (2005). Pathological gambling caused by drugs used to treat Parkinson disease. Archives of Neurology, 62(9), 1377-1381. https://doi.org/10.1001/archneur.62.9.noc50009

Dube, S. R., Anda, R. F., Felitti, V. J., Edwards, V. J., \& Croft, J. B. (2002). Adverse childhood experiences and personal alcohol abuse as an adult. Addictive Behaviors, 27(5), 713-725. https://doi.org/10. 1016/S0306-4603(01)00204-0

Dube, S. R., Miller, J. W., Brown, D. W., Giles, W. H., Felitti, V. J., Dong, M., \& Anda, R. F. (2006). Adverse childhood experiences and the association with ever using alcohol and initiating alcohol use during adolescence. The Journal of Adolescent Health : Official Publication of the Society for Adolescent Medicine, 38(4), 444.e110. https://doi.org/10.1016/j.jadohealth.2005.06.006

Edens, E. L., \& Rosenheck, R. A. (2011). Rates and Correlates of Pathological Gambling Among VA Mental Health Service Users. Journal of Gambling Studies / Co-Sponsored by the National Council on Problem Gambling and Institute for the Study of Gambling and Commercial Gaming, 28(1), 1-11. https://doi.org/ 10.1007/s10899-011-9239-z

Eisener-Dorman, A. F., Grabowski-Boase, L., \& Tarantino, L. M. (2011). Cocaine locomotor activation, sensitization and place preference in six inbred strains of mice. Behavioral and Brain Functions : BBF, 7(1), 29. https://doi.org/10.1186/1744-9081-7-29

el-Guebaly, N., Patten, S. B., Currie, S., Williams, J. V. A., Beck, C. A., Maxwell, C. J., \& Wang, J. L. (2006). Epidemiological Associations between Gambling Behavior, Substance Use \& Mood and Anxiety Disorders. Journal of Gambling Studies / Co-Sponsored by the National Council on Problem Gambling and Institute for the Study of Gambling and Commercial Gaming, 22(3), 275-287. https://doi. org/10.1007/s10899-006-9016-6

Elman, I., Becerra, L., Tschibelu, E., Yamamoto, R., George, E., \& Borsook, D. (2012). Yohimbine-induced amygdala activation in pathological gamblers: a pilot study. PloS One, 7(2), e31118. https://doi.org/10.1371/journal.pone.0031118

Elman, I., Tschibelu, E., \& Borsook, D. (2010). Psychosocial stress and its relationship to gambling urges in individuals with pathological gambling. The American Journal on Addictions, 19(4), 332-339. https://doi.org/10.1111/j.1521-0391.2010.00055.x

Enoch, M.-A. (2011). The role of early life stress as a predictor for alcohol and drug dependence. Psychopharmacology, 214(1), 17-31. https:// doi.org/10.1007/s00213-010-1916-6

Evans, A. H., Lawrence, A. D., Cresswell, S. A., Katzenschlager, R., \& Lees, A. J. (2010). Compulsive use of dopaminergic drug therapy in Parkinson's disease: reward and anti-reward. Movement Disorders : Official Journal of the Movement Disorder Society, 25(7), 867-876. https://doi.org/10.1002/mds.22898

Evans, A. H., Pavese, N., Lawrence, A. D., Tai, Y. F., Appel, S., Doder, M., et al. (2006). Compulsive drug use linked to sensitized ventral striatal dopamine transmission. Annals of Neurology, 59(5), 852858. https://doi.org/10.1002/ana.20822

Felsher, J. R., Derevensky, J. L., \& Gupta, R. (2004). Lottery playing amongst youth: implications for prevention and social policy. Journal of Gambling Studies, 20(2), 127-153. https://doi.org/10. 1023/B:JOGS.0000022306.72513.7c

Ferland, J.-M. N., \& Winstanley, C. A. (2016). Risk-preferring rats make worse decisions and show increased incubation of craving after cocaine self-administration. Addiction Biology, 22(4), 991-1001. https://doi.org/10.1111/adb.12388
Ferrario, C. R., Gorny, G., Crombag, H. S., Li, Y., Kolb, B., \& Robinson, T. E. (2005). Neural and behavioral plasticity associated with the transition from controlled to escalated cocaine use. Biological Psychiatry, 58(9), 751-759. https://doi.org/10.1016/j.biopsych. 2005.04 .046

Ferrario, C. R., \& Robinson, T. E. (2007). Amphetamine pretreatment accelerates the subsequent escalation of cocaine self-administration behavior. European Neuropsychopharmacology, 17(5), 352-357. https://doi.org/10.1016/j.euroneuro.2006.08.005

Fiorillo, C. D. (2011). Transient activation of midbrain dopamine neurons by reward risk. Neuroscience, 197, 162-171. https://doi.org/10. 1016/j.neuroscience.2011.09.037

Fiorillo, C. D., Tobler, P. N., \& Schultz, W. (2003). Discrete coding of reward probability and uncertainty by dopamine neurons. Science, 299(5614), 1898-1902. https://doi.org/10.1126/science.1077349

Fischman, M. W., \& Foltin, R. W. (1992). Self-administration of cocaine by humans: a laboratory perspective. Ciba Foundation Symposium, $166,165-180$.

Fox, H. C., Bergquist, K. L., Hong, K.-I., \& Sinha, R. (2007). Stressinduced and alcohol cue-induced craving in recently abstinent alcohol-dependent individuals. Alcoholism, Clinical and Experimental Research, 31(3), 395-403. https://doi.org/10.1111/j. 1530-0277.2006.00320.x

Franken, I. H., de Haan, H. A., van der Meer, C. W., Haffmans, P. M., \& Hendriks, V. M. (1999). Cue reactivity and effects of cue exposure in abstinent posttreatment drug users. Journal of Substance Abuse Treatment, 16(1), 81-85. https://doi.org/10.1016/S0740-5472(98) 00004-X

Garcia-Keller, C., Martinez, S. A., Esparza, M. A., Bollati, F., Kalivas, P. W., \& Cancela, L. M. (2013). Cross-sensitization between cocaine and acute restraint stress is associated with sensitized dopamine but not glutamate release in the nucleus accumbens. European Journal of Neuroscience, 37(6), 982-995. https://doi.org/10.1111/ejn.12121

Gerstein, D. R., Hoffmann, J. P., \& Larison, C. (1999). Gambling impact and behavior study: Report to the national gambling impact study commission.

Giddens, J. L., Stefanovics, E., Pilver, C. E., Desai, R., \& Potenza, M. N. (2012). Pathological gambling severity and co-occurring psychiatric disorders in individuals with and without anxiety disorders in a nationally representative sample. Psychiatry Research, 199(1), 5864. https://doi.org/10.1016/j.psychres.2012.03.052

Gorka, S. M., Nelson, B. D., Phan, K. L., \& Shankman, S. A. (2016). Intolerance of uncertainty and insula activation during uncertain reward. Cognitive, Affective \& Behavioral Neuroscience, 16(5), 929-939. https://doi.org/10.3758/s13415-016-0443-2

Goudriaan, A. E., Yucel, M., \& van Holst, R. J. (2014). Getting a grip on problem gambling: What can neuroscience tell us? Frontiers in Behavioral Neuroscience, 1-29.

Govind, A. P., Vezina, P., \& Green, W. N. (2009). Nicotine-induced upregulation of nicotinic receptors: underlying mechanisms and relevance to nicotine addiction. Biochemical Pharmacology, 78(7), 756-765. https://doi.org/10.1016/j.bcp.2009.06.011

Grant, B. F., Hasin, D. S., Chou, S. P., Stinson, F. S., \& Dawson, D. A. (2004a). Nicotine dependence and psychiatric disorders in the United States: results from the national epidemiologic survey on alcohol and related conditions. Archives of General Psychiatry, 61(11), 1107-1115. https://doi.org/10.1001/archpsyc.61.11.1107

Grant, B. F., Stinson, F. S., Dawson, D. A., Chou, S. P., Dufour, M. C., Compton, W., et al. (2004b). Prevalence and co-occurrence of substance-use disorders and independent mood and anxiety disorders: results from the National Epidemiologic Survey on Alcohol and Related Conditions. Archives of General Psychiatry, 61(8), 807-816. https://doi.org/10.1001/archpsyc.61.8.807

Grant, J. E., \& Potenza, M. N. (2005). Tobacco Use and Pathological Gambling. Annals of Clinical Psychiatry, 17(4). https://doi.org/10. 3109/10401230500295370 
Grant, J. E., Williams, K. A., \& Kim, S. W. (2006). Update on pathological gambling. Current Psychiatry Reports, 8(1), 53-58.

Grant, L. D., \& Bowling, A. C. (2015). Gambling Attitudes and Beliefs Predict Attentional Bias in Non-problem Gamblers. Journal of Gambling Studies / Co-Sponsored by the National Council on Problem Gambling and Institute for the Study of Gambling and Commercial Gaming, 31(4), 1487-1503. https://doi.org/10.1007/ s10899-014-9468-z

Green, C. L., Nahhas, R. W., Scoglio, A. A., \& Elman, I. (2017). Posttraumatic stress symptoms in pathological gambling: Potential evidence of anti-reward processes. Journal of Behavioral Addictions, 6(1), 98-101. https://doi.org/10.1556/2006.6.2017.006

Green, J. G., McLaughlin, K. A., Berglund, P. A., Gruber, M. J., Sampson, N. A., Zaslavsky, A. M., \& Kessler, R. C. (2010). Childhood adversities and adult psychiatric disorders in the national co-mordidity survey replication I: associations with first onset of DSM-IV disorders. Archives of General Psychiatry, 67(2), 113123. https://doi.org/10.1001/archgenpsychiatry.2009.186

Griffiths, M. (1993). Fruit machine gambling: The importance of structural characteristics. Journal of Gambling Studies, 9(2), 101-120. https://doi.org/10.1007/BF01014863

Grupe, D. W., \& Nitschke, J. B. (2013). Uncertainty and anticipation in anxiety: an integrated neurobiological and psychological perspective. Nature Reviews Neuroscience, 14(7), 488-501. https://doi.org/ $10.1038 / \mathrm{nrn} 3524$

Hasin, D. S., Stinson, F. S., Ogburn, E., \& Grant, B. F. (2007). Prevalence, correlates, disability, and co-mordidity of DSM-IV alcohol abuse and dependence in the United States: results from the National Epidemiologic Survey on Alcohol and Related Conditions. Archives of General Psychiatry, 64(7), 830-842. https://doi.org/10. 1001/archpsyc.64.7.830

Heeren, A., Peschard, V., \& Philippot, P. (2011). The Causal Role of Attentional Bias for Threat Cues in Social Anxiety: A Test on a Cyber-Ostracism Task. Cognitive Therapy and Research, 36(5), 512-521. https://doi.org/10.1007/s10608-011-9394-7

Hefner, K. R., Moberg, C. A., Hachiya, L. Y., \& Curtin, J. J. (2013). Alcohol stress response dampening during imminent versus distal, uncertain threat. Journal of Abnormal Psychology, 122(3), 756-769. https://doi.org/10.1037/a0033407

Heinz, A., Siessmeier, T., Wrase, J., Hermann, D., Klein, S., GrüsserSinopoli, S. M., et al. (2014). Correlation Between Dopamine D2 Receptors in the Ventral Striatum and Central Processing of Alcohol Cues and Craving. American Journal of Psychiatry, 161(10), 17831789. https://doi.org/10.1176/ajp.161.10.1783

Hellberg, S. N., Levit, J. D., \& Robinson, M. J. F. (2018). Under the influence: Effects of adolescent ethanol exposure and anxiety on motivation for uncertain gambling-like cues in male and female rats. Behavioural Brain Research, 337, 17-33. https://doi.org/10.1016/j. bbr.2017.09.036

Hickey, C., \& Peelen, M. V. (2015). Neural Mechanisms of Incentive Salience in Naturalistic Human Vision. Neuron, 85(3), 512-518. https://doi.org/10.1016/j.neuron.2014.12.049

Hobbs, M., Remington, B., \& Glautier, S. (2005). Dissociation of wanting and liking for alcohol in humans: a test of the incentivesensitisation theory. Psychopharmacology, 178(4), 493-499. https://doi.org/10.1007/s00213-004-2026-0

Holly, E. N., Shimamoto, A., DeBold, J. F., \& Miczek, K. A. (2012). Sex differences in behavioral and neural cross-sensitization and escalated cocaine taking as a result of episodic social defeat stress in rats. Psychopharmacology, 224(1), 179-188. https://doi.org/10.1007/ s00213-012-2846-2

Hønsi, A., Mentzoni, R. A., Molde, H., \& Pallesen, S. (2012). Attentional Bias in Problem Gambling: A Systematic Review. Journal of Gambling Studies / Co-Sponsored by the National Council on Problem Gambling and Institute for the Study of Gambling and
Commercial Gaming, 29(3), 359-375. https://doi.org/10.1007/ s10899-012-9315-z

Horger, B. A., Giles, M. K., \& Schenk, S. (1992). Preexposure to amphetamine and nicotine predisposes rats to self-administer a low dose of cocaine. Psychopharmacology, 107(2-3), 271-276.

Hoshaw, B. A., \& Lewis, M. J. (2001). Behavioral sensitization to ethanol in rats: evidence from the Sprague-Dawley strain. Pharmacology, Biochemistry, and Behavior, 68(4), 685-690.

Hudson, A., Olatunji, B. O., Gough, K., Yi, S., \& Stewart, S. H. (2016). Eye on the Prize: High-Risk Gamblers Show Sustained Selective Attention to Gambling Cues. Journal of Gambling Issues, 34, 100-119. https://doi.org/10.4309/jgi.2016.34.6

Hynes, T. J., Thomas, C. S., Zumbusch, A. S., Samson, A., Petriman, I., Mrdja, U., et al. (2017). Early life adversity potentiates expression of addiction-related traits. Progress in Neuro-Psychopharmacology \& Biological Psychiatry. https://doi.org/10.1016/j.pnpbp.2017.09.005

Isomura, T., Suzuki, J., \& Murai, T. (2014). Paradise Lost: The relationships between neurological and psychological changes in nicotinedependent patients. Addiction Research \& Theory, 22(2), 158-165. https://doi.org/10.3109/16066359.2013.793312

Janes, A. C., Pizzagalli, D. A., Richardt, S., deB Frederick, B., Chuzi, S., Pachas, G., et al. (2010). Brain reactivity to smoking cues prior to smoking cessation predicts ability to maintain tobacco abstinence. Biological Psychiatry, 67(8), 722-729. https://doi.org/10.1016/j. biopsych.2009.12.034

Joutsa, J., Johansson, J., Niemelä, S., Ollikainen, A., Hirvonen, M. M., Piepponen, P., et al. (2012). Mesolimbic dopamine release is linked to symptom severity in pathological gambling. NeuroImage, 60(4), 1992-1999. https://doi.org/10.1016/j.neuroimage.2012.02.006

Kausch, O., Rugle, L., \& Rowland, D. Y. (2006). Lifetime histories of trauma among pathological gamblers. The American Journal on Addictions, 15(1), 35-43. https://doi.org/10.1080/ 10550490500419045

Kennedy, S. H., Welsh, B. R., Fulton, K., Soczynska, J. K., McIntyre, R. S., O'Donovan, C., et al. (2010). Frequency and correlates of gambling problems in outpatients with major depressive disorder and bipolar disorder. The Canadian Journal of Psychiatry, 55(9), 568576. https://doi.org/10.1177/070674371005500905

Kessler, R. C., Chiu, W. T., Demler, O., \& Walters, E. E. (2005). Prevalence, Severity, and Comorbidity of 12-Month DSM-IV Disorders in the National Comorbidity Survey Replication. Archives of General Psychiatry, 62(6), 617-627. https://doi.org/10. 1001/archpsyc.62.6.617

Kessler, R. C., Hwang, I., LaBrie, R., Petukhova, M., Sampson, N. A., Winters, K. C., \& Shaffer, H. J. (2008). DSM-IV pathological gambling in the National Comorbidity Survey Replication. Psychological Medicine, 38(9), 1351-1360. https://doi.org/10. 1017/S0033291708002900

Kessler, R. C., McGonagle, K. A., Zhao, S., Nelson, C. B., Hughes, M., Eshleman, S., et al. (1994). Lifetime and 12-month prevalence of DSM-III-R psychiatric disorders in the United States. Results from the National Comorbidity Survey. Archives of General Psychiatry, $51(1), 8-19$.

Kim, W. Y., Cho, B. R., Kwak, M. J., \& Kim, J.-H. (2017). Interaction between trait and housing condition produces differential decisionmaking toward risk choice in a rat gambling task. Scientific Reports, 7(1), 5718. https://doi.org/10.1038/s41598-017-06408-4

King, D. L., Delfabbro, P. H., Zwaans, T., \& Kaptsis, D. (2013). Clinical features and axis I comorbidity of Australian adolescent pathological Internet and video game users. Australian \& New Zealand Journal of Psychiatry, 47(11), 1058-1067. https://doi.org/10.1177/ 0004867413491159

King, A. C., Hasin, D., O'Connor, S. J., McNamara, P. J., \& Cao, D. (2016). A Prospective 5-Year Re-examination of Alcohol Response in Heavy Drinkers Progressing in Alcohol Use Disorder. 
Biological Psychiatry, 79(6), 489-498. https://doi.org/10.1016/j. biopsych.2015.05.007

Kluen, L. M., Agorastos, A., Wiedemann, K., \& Schwabe, L. (2017). Cortisol boosts risky decision-making behavior in men but not in women. Psychoneuroendocrinology, 84, 181-189. https://doi.org/ 10.1016/j.psyneuen.2017.07.240

Koot, S., Baars, A., Hesseling, P., van den Bos, R., \& Joëls, M. (2013). Time-dependent effects of corticosterone on reward-based decisionmaking in a rodent model of the Iowa Gambling Task. Neuropharmacology, 70, 306-315. https://doi.org/10.1016/j. neuropharm.2013.02.008

Krain, A. L., Hefton, S., Pine, D. S., Ernst, M., Castellanos, F. X., Klein, R. G., \& Milham, M. P. (2006). An fMRI examination of developmental differences in the neural correlates of uncertainty and decision-making. Journal of Child Psychology and Psychiatry, and Allied Disciplines, 47(10), 1023-1030. https://doi.org/10.1111/j. 1469-7610.2006.01677.x

Krank, M. D. (2003). Pavlovian conditioning with ethanol: sign-tracking (autoshaping), conditioned incentive, and ethanol self-administration. Alcoholism, Clinical and Experimental Research, 27(10), 1592-1598. https://doi.org/10.1097/01.ALC.0000092060.09228. $\mathrm{DE}$

Krank, M. D., O'Neill, S., Squarey, K., \& Jacob, J. (2008). Goal- and signal-directed incentive: conditioned approach, seeking, and consumption established with unsweetened alcohol in rats. Psychopharmacology, 196(3), 397-405. https://doi.org/10.1007/ s00213-007-0971-0

Krmpotich, T., Mikulich-Gilbertson, S., Sakai, J., Thompson, L., Banich, M. T., \& Tanabe, J. (2015). Impaired Decision-Making, Higher Impulsivity, and Drug Severity in Substance Dependence and Pathological Gambling. Journal of Addiction Medicine, 9(4), 273 280. https://doi.org/10.1097/ADM.0000000000000129

Kushner, M., Thurus, P., Sletten, S., Frye, B., Abrams, K., Adson, D., et al. (2008). Urge to Gamble in a Simulated Gambling Environment. Journal of Gambling Studies / Co-Sponsored by the National Council on Problem Gambling and Institute for the Study of Gambling and Commercial Gaming, 24(2), 219-227. https://doi. org/10.1007/s10899-007-9083-3

Ladd, G. T., \& Petry, N. M. (2003). A comparison of pathological gamblers with and without substance abuse treatment histories. Experimental and Clinical Psychopharmacology, 11(3), 202-209. https://doi.org/10.1037/1064-1297.11.3.202

Laviolette, S. R., \& van der Kooy, D. (2004). The neurobiology of nicotine addiction: bridging the gap from molecules to behaviour. Nature Reviews Neuroscience, 5(1), 55-65. https://doi.org/10.1038/ nrn1298

Lê, A. D., Quan, B., Juzytch, W., Fletcher, P. J., Joharchi, N., \& Shaham, Y. (1998). Reinstatement of alcohol-seeking by priming injections of alcohol and exposure to stress in rats. Psychopharmacology, 135(2), 169-174.

Ledgerwood, D. M., \& Petry, N. M. (2006). Posttraumatic stress disorder symptoms in treatment-seeking pathological gamblers. Journal of Traumatic Stress, 19(3), 411-416. https://doi.org/10.1002/jts.20123

Ledgerwood, D. M., \& Petry, N. M. (2010). Subtyping pathological gamblers based on impulsivity, depression, and anxiety. Psychology of Addictive Behaviors, 24(4), 680-688. https://doi.org/10.1037/ a0019906

Leeman, R. F., \& Potenza, M. N. (2012). Similarities and differences between pathological gambling and substance-use disorders: a focus on impulsivity and compulsivity. Psychopharmacology, 219(2), 469-490. https://doi.org/10.1007/s00213-011-2550-7

Leeman, R. F., \& Potenza, M. N. (2013). A Targeted Review of the Neurobiology and Genetics of Behavioural Addictions: An Emerging Area of Research. The Canadian Journal of Psychiatry, 58(5), 260-273. https://doi.org/10.1177/070674371305800503
Leyton, M. (2007). Conditioned and sensitized responses to stimulant drugs in humans. Progress in Neuro-Psychopharmacology \& Biological Psychiatry, 31(8), 1601-1613. https://doi.org/10.1016/j. pnpbp.2007.08.027

Leyton, M. (2014). What's deficient in reward deficiency? Journal of Psychiatry \& Neuroscience, 39(5), 291-293.

Leyton, M., Boileau, I., Benkelfat, C., Diksic, M., Baker, G. B., \& Dagher, A. (2002). Amphetamine-induced increases in extracellular dopamine, drug wanting, and novelty seeking: a PET/ [11C]raclopride study in healthy men. Neuropsychopharmacology, 27(6), 1027-1035. https://doi.org/10.1016/S0893-133X(02)00366-

Leyton, M., \& Vezina, P. (2012). On cue: striatal ups and downs in addictions. Biological Psychiatry, 72(10), e21-2. https://doi.org/ 10.1016/j.biopsych.2012.04.036

Leyton, M., \& Vezina, P. (2014). Dopamine ups and downs in vulnerability to addictions: a neurodevelopmental model. Trends in Pharmacological Sciences, 35(6), 268-276. https://doi.org/10. 1016/j.tips.2014.04.002

Linnet, J. (2014). Neurobiological underpinnings of reward anticipation and outcome evaluation in gambling disorder. Frontiers in Behavioral Neuroscience, 8, 100. https://doi.org/10.3389/fnbeh. 2014.00100/abstract

Linnet, J., Møller, A., Peterson, E., Gjedde, A., \& Doudet, D. (2011). Dopamine release in ventral striatum during Iowa Gambling Task performance is associated with increased excitement levels in pathological gambling. Addiction, 106(2), 383-390. https://doi.org/10. 1111/j.1360-0443.2010.03126.x

Linnet, J., Mouridsen, K., Peterson, E., Møller, A., Doudet, D. J., \& Gjedde, A. (2012). Striatal dopamine release codes uncertainty in pathological gambling. Psychiatry Research, 204(1), 55-60. https:// doi.org/10.1016/j.pscychresns.2012.04.012

Linnet, J., Peterson, E., Doudet, D. J., Gjedde, A., \& Møller, A. (2010). Dopamine release in ventral striatum of pathological gamblers losing money. Acta Psychiatrica Scandinavica, 122(4), 326-333. https://doi.org/10.1111/j.1600-0447.2010.01591.x

Lister, J. J., Milosevic, A., \& Ledgerwood, D. M. (2015). Psychological Characteristics of Problem Gamblers With and Without Mood Disorder. The Canadian Journal of Psychiatry, 60(8), 369-376. https://doi.org/10.1177/070674371506000806

Littel, M., Franken, I. H. A., \& Van Strien, J. W. (2009). Changes in the electroencephalographic spectrum in response to smoking cues in smokers and ex-smokers. Neuropsychobiology, 59(1), 43-50. https://doi.org/10.1159/000205517

Lopez, M. F., Doremus-Fitzwater, T. L., \& Becker, H. C. (2011). Chronic social isolation and chronic variable stress during early development induce later elevated ethanol intake in adult $\mathrm{C} 57 \mathrm{BL} / 6 \mathrm{~J}$ mice. Alcohol, 45(4), 355-364. https://doi.org/10.1016/j.alcohol.2010.08. 017

Lorains, F. K., Cowlishaw, S., \& Thomas, S. A. (2011). Prevalence of comordid disorders in problem and pathological gambling: systematic review and meta-analysis of population surveys. Addiction, 106(3), 490-498. https://doi.org/10.1111/j.1360-0443.2010.03300.x

Madayag, A. C., Stringfield, S. J., Reissner, K. J., Boettiger, C. A., \& Robinson, D. L. (2017). Sex and Adolescent Ethanol Exposure Influence Pavlovian Conditioned Approach. Alcoholism, Clinical and Experimental Research, 41(4), 846-856. https://doi.org/10. 1111/acer.13354

Mahoney, A. E. J., \& McEvoy, P. M. (2012). A transdiagnostic examination of intolerance of uncertainty across anxiety and depressive disorders. Cognitive Behaviour Therapy, 41(3), 212-222. https://doi. org/10.1080/16506073.2011.622130

Mantsch, J. R., Baker, D. A., Funk, D., Lê, A. D., \& Shaham, Y. (2016). Stress-Induced Reinstatement of Drug Seeking: 20 Years of Progress. Neuropsychopharmacology, 41(1), 335-356. https://doi. org/10.1038/npp.2015.142 
Marhe, R., Luijten, M., van de Wetering, B. J. M., Smits, M., \& Franken, I. H. A. (2013). Individual Differences in Anterior Cingulate Activation Associated with Attentional Bias Predict Cocaine Use After Treatment. Neuropsychopharmacology, 38(6), 1085-1093. https://doi.org/10.1038/npp.2013.7

Mascia, P., Neugebauer, N. M., Brown, J., Bubula, N., Nesbitt, K. M., Kennedy, R. T., \& Vezina, P. (2018). Exposure to conditions of uncertainty promotes the pursuit of amphetamine. Neuropsychopharmacology, 1-7. https://doi.org/10.1038/s41386018-0099-4

Matheny, K. B., \& Weatherman, K. E. (1998). Predictors of smoking cessation and maintenance. Journal of Clinical Psychology, 54(2), 223-235. https://doi.org/10.1002/(SICI)1097-4679(199802)54: $2<223::$ AID-JCLP12>3.0.CO;2-L

Matsumoto, M., \& Hikosaka, O. (2009). Two types of dopamine neuron distinctly convey positive and negative motivational signals. Nature, 459(7248), 837-841. https://doi.org/10.1038/nature08028

McCormick, C. M., Robarts, D., Gleason, E., \& Kelsey, J. E. (2004). Stress during adolescence enhances locomotor sensitization to nicotine in adulthood in female, but not male, rats. Hormones and Behavior, 46(4), 458-466. https://doi.org/10.1016/j.yhbeh.2004. 05.004

McGrath, D. S., \& Barrett, S. P. (2009). The co-mordidity of tobacco smoking and gambling: a review of the literature. Drug and Alcohol Review, 28(6), 676-681. https://doi.org/10.1111/j.14653362.2009.00097.x

McGrath, D. S., Dorbeck, A., \& Barrett, S. P. (2013). The influence of acutely administered nicotine on cue-induced craving for gambling in at-risk video lottery terminal gamblers who smoke. Behavioural Pharmacology, 24(2), 124-132. https://doi.org/10.1097/FBP. $0 \mathrm{~b} 013 \mathrm{e} 32835 \mathrm{f} 3 \mathrm{cff}$

McGrath, D. S., Meitner, A., \& Sears, C. R. (2018). The specificity of attentional biases by type of gambling: An eye-tracking study. PloS One, 13(1), e0190614-16. https://doi.org/10.1371/journal.pone. 0190614

McLaughlin, K. A., Conron, K. J., Koenen, K. C., \& Gilman, S. E. (2010). Childhood adversity, adult stressful life events, and risk of past-year psychiatric disorder: a test of the stress sensitization hypothesis in a population-based sample of adults. Psychological Medicine, 40(10), 1647-1658. https://doi.org/10.1017/ S0033291709992121

Mick, I., Myers, J., Ramos, A. C., Stokes, P. R. A., Erritzoe, D., Colasanti, A., et al. (2016). Blunted Endogenous Opioid Release Following an Oral Amphetamine Challenge in Pathological Gamblers. Neuropsychopharmacology, 41(7), 1742-1750. https://doi.org/10. 1038/npp.2015.340

Miedl, S. F., Büchel, C., \& Peters, J. (2014). Cue-Induced Craving Increases Impulsivity via Changes in Striatal Value Signals in Problem Gamblers. The Journal of Neuroscience: the Official Journal of the Society for Neuroscience, 34(13), 4750-4755. https://doi.org/10.1523/JNEUROSCI.5020-13.2014

Miedl, S. F., Peters, J., \& Büchel, C. (2012). Altered neural reward representations in pathological gamblers revealed by delay and probability discounting. Archives of General Psychiatry, 69(2), 177-186. https://doi.org/10.1001/archgenpsychiatry.2011.1552

Milosevic, A., \& Ledgerwood, D. M. (2010). The subtyping of pathological gambling: a comprehensive review. Clinical Psychology Review, 30(8), 988-998. https://doi.org/10.1016/j.cpr.2010.06.013

Mogg, K., \& Bradley, B. P. (2018). Anxiety and Threat-Related Attention: Cognitive-Motivational Framework and Treatment. Trends in Cognitive Sciences, 22(3), 225-240. https://doi.org/10. 1016/j.tics.2018.01.001

Moghaddam, J. F., Yoon, G., Campos, M. D., \& Fong, T. W. (2015). Social and behavioral problems among five gambling severity groups. Psychiatry Research, 230(2), 143-149. https://doi.org/10. 1016/j.psychres.2015.07.082
Munafò, M. R., Mannie, Z. N., Cowen, P. J., Harmer, C. J., \& McTavish, S. B. (2007). Effects of acute tyrosine depletion on subjective craving and selective processing of smoking-related cues in abstinent cigarette smokers. Journal of Psychopharmacology (Oxford, England), 21(8), 805-814. https://doi.org/10.1177/ 0269881107077216

Najavits, L. M., Meyer, T., Johnson, K. M., \& Korn, D. (2011). Pathological gambling and posttraumatic stress disorder: a study of the co-morbidity versus each alone. Journal of Gambling Studies $/$ Co-Sponsored by the National Council on Problem Gambling and Institute for the Study of Gambling and Commercial Gaming, 27(4), 663-683. https://doi.org/10.1007/s10899-010-9230-0

Nautiyal, K. M., Okuda, M., Hen, R., \& Blanco, C. (2017). Gambling disorder: an integrative review of animal and human studies. Annals of the New York Academy of Sciences, 1394(1), 106-127. https://doi. org/10.1111/nyas.13356

Nelson, B. D., \& Shankman, S. A. (2011). Does intolerance of uncertainty predict anticipatory startle responses to uncertain threat? International Journal of Psychophysiology : Official Journal of the International Organization of Psychophysiology, 81(2), 107115. https://doi.org/10.1016/j.ijpsycho.2011.05.003

Neugebauer, N. M., Cortright, J. J., Sampedro, G. R., \& Vezina, P. (2014). Exposure to nicotine enhances its subsequent self-administration: contribution of nicotine-associated contextual stimuli. Behavioural Brain Research, 260, 155-161. https://doi.org/10.1016/j.bbr.2013. 11.035

Noseworthy, T. J., \& Finlay, K. (2009). A comparison of ambient casino sound and music: effects on dissociation and on perceptions of elapsed time while playing slot machines. Journal of Gambling Studies / Co-Sponsored by the National Council on Problem Gambling and Institute for the Study of Gambling and Commercial Gaming, 25(3), 331-342. https://doi.org/10.1007/ s10899-009-9136-x

Ostafin, B. D., Marlatt, G. A., \& Troop-Gordon, W. (2010). Testing the incentive-sensitization theory with at-risk drinkers: wanting, liking, and alcohol consumption. Psychology of Addictive Behaviors, 24(1), 157-162. https://doi.org/10.1037/a0017897

Palmatier, M. I., Kellicut, M. R., Brianna Sheppard, A., Brown, R. W., \& Robinson, D. L. (2014). The incentive amplifying effects of nicotine are reduced by selective and non-selective dopamine antagonists in rats. Pharmacology, Biochemistry, and Behavior, 126, 50-62. https://doi.org/10.1016/j.pbb.2014.08.012

Parhami, I., Mojtabai, R., Rosenthal, R. J., Afifi, T. O., \& Fong, T. W. (2014). Gambling and the Onset of Comorbid Mental Disorders. Journal of Psychiatric Practice, 20(3), 207-219. https://doi.org/10. 1097/01.pra.0000450320.98988.7c

Park, C.-B., Park, S. M., Gwak, A. R., Sohn, B. K., Lee, J.-Y., Jung, H. Y., et al. (2015). The effect of repeated exposure to virtual gambling cues on the urge to gamble. Addictive Behaviors, 41, 61-64. https:// doi.org/10.1016/j.addbeh.2014.09.027

Parke, J., \& Griffiths, M. (2006). The Psychology of the Fruit Machine: The Role of Structural Characteristics (Revisited). International Journal of Mental Health and Addiction, 4(2), 151-179. https:// doi.org/10.1007/s11469-006-9014-z

Paulson, P. E., Camp, D. M., \& Robinson, T. E. (1991). Time course of transient behavioral depression and persistent behavioral sensitization in relation to regional brain monoamine concentrations during amphetamine withdrawal in rats. Psychopharmacology, 103(4), 480-492. https://doi.org/10.1007/BF02244248

Peciña, S., \& Berridge, K. C. (2013). Dopamine or opioid stimulation of nucleus accumbens similarly amplify cue-triggered "wanting" for reward: entire core and medial shell mapped as substrates for PIT enhancement. The European Journal of Neuroscience, 37(9), 1529 1540. https://doi.org/10.1111/ejn.12174

Peciña, S., Cagniard, B., Berridge, K. C., Aldridge, J. W., \& Zhuang, X. (2003). Hyperdopaminergic mutant mice have higher "wanting" but 
not 'liking' for sweet rewards. The Journal of Neuroscience, 23(28), 9395-9402.

Peciña, S., Schulkin, J., \& Berridge, K. C. (2006). Nucleus accumbens corticotropin-releasing factor increases cue-triggered motivation for sucrose reward: paradoxical positive incentive effects in stress? BMC Biology, 4(1), 8. https://doi.org/10.1186/1741-7007-4-8

Perkins, K. A., \& Grobe, J. E. (1992). Increased desire to smoke during acute stress. British Journal of Addiction, 87(7), 1037-1040.

Petry, N. M., \& Armentano, C. (1999). Prevalence, assessment, and treatment of pathological gambling: a review. Psychiatric Services (Washington, D.C.), 50(8), 1021-1027. https://doi.org/10.1176/ps. 50.8.1021

Petry, N. M., \& Blanco, C. (2013). National gambling experiences in the United States: will history repeat itself? Addiction, 108(6), 10321037. https://doi.org/10.1111/j.1360-0443.2012.03894.x

Petry, N. M., \& Kiluk, B. D. (2002). Suicidal ideation and suicide attempts in treatment-seeking pathological gamblers. The Journal of Nervous and Mental Disease, 190(7), 462-469. https://doi.org/10. 1097/01.NMD.0000022447.27689.96

Petry, N. M., \& Oncken, C. (2002). Cigarette smoking is associated with increased severity of gambling problems in treatment-seeking gamblers. Addiction, 97(6), 745-753.

Petry, N. M., Stinson, F. S., \& Grant, B. F. (2005). Comorbidity of DSMIV Pathological Gambling and Other Psychiatric Disorders. The Journal of Clinical Psychiatry, 66(05), 564-574. https://doi.org/10. 4088/JCP.v66n0504

Phillips, T. J. (1997). Behavior Genetics of Drug Sensitization. Critical Reviews\&Trade; in Neurobiology, 11(1), 21-33. https://doi.org/10. 1615/CritRevNeurobiol.v11.i1.20

Phillips, T. J., Huson, M., Gwiazdon, C., Kasch, S. B., \& Shen, E. H. (1995). Effects of Acute and Repeated Ethanol Exposures on the Locomotor Activity of BXD Recombinant Inbred Mice. Alcoholism, Clinical and Experimental Research, 19(2), 269-278. https://doi.org/10.1111/j.1530-0277.1995.tb01502.x

Phillips, T. J., Huson, M. G., \& McKinnon, C. S. (1998). Localization of genes mediating acute and sensitized locomotor responses to cocaine in $\mathrm{BXD} / \mathrm{Ty}$ recombinant inbred mice. The Journal of Neuroscience: the Official Journal of the Society for Neuroscience, 18(8), 3023-3034.

Piazza, P. V., Deminiere, J. M., le Moal, M., \& Simon, H. (1990). Stressand pharmacologically-induced behavioral sensitization increases vulnerability to acquisition of amphetamine self-administration. Brain Research, 514(1), 22-26.

Possemato, K., Maisto, S. A., Wade, M., Barrie, K., McKenzie, S., Lantinga, L. J., \& Ouimette, P. (2015). Ecological momentary assessment of PTSD symptoms and alcohol use in combat veterans. Psychology of Addictive Behaviors, 29(4), 894-905. https://doi.org/ 10.1037/adb0000129

Potenza, M. N. (2008). The Neurobiology of Pathological Gambling and Drug Addiction: An Overview and New Findings. Philosophical Transactions: Biological Sciences, 363(1507), 3181-3189.

Potenza, M. N., Fiellin, D. A., Heninger, G. R., Rounsaville, B. J., \& Mazure, C. M. (2002). Gambling: an addictive behavior with health and primary care implications. Journal of General Internal Medicine, 17(9), 721-732. https://doi.org/10.1046/j.1525-1497. 2002.10812.x

Potenza, M. N., Steinberg, M. A., McLaughlin, S. D., Wu, R., Rounsaville, B. J., Krishnan-Sarin, S., et al. (2004). Characteristics of tobacco-smoking problem gamblers calling a gambling helpline. The American Journal on Addictions, 13(5), 471-493. https://doi. org/10.1080/10550490490483044

Potenza, M. N., Steinberg, M. A., Skudlarski, P., Fulbright, R. K., Lacadie, C. M., Wilber, M. K., et al. (2003). Gambling urges in pathological gambling: a functional magnetic resonance imaging study. Archives of General Psychiatry, 60(8), 828-836. https://doi. org/10.1001/archpsyc.60.8.828
Powell, Jane, Dawkins, L., West, R., Powell, J., \& Pickering, A. (2010). Relapse to smoking during unaided cessation: clinical, cognitive and motivational predictors. Psychopharmacology, 212(4), 537-549. https://doi.org/10.1007/s00213-010-1975-8

Reed, S. C., Haney, M., Evans, S. M., Vadhan, N. P., Rubin, E., \& Foltin, R. W. (2009). Cardiovascular and subjective effects of repeated smoked cocaine administration in experienced cocaine users. Drug and Alcohol Dependence, 102(1-3), 102-107. https://doi.org/10. 1016/j.drugalcdep.2009.02.004

Rennert, L., Denis, C., Peer, K., Lynch, K. G., Gelernter, J., \& Kranzler, H. R. (2014). DSM-5 gambling disorder: prevalence and characteristics in a substance-use disorder sample. Experimental and Clinical Psychopharmacology, 22(1), 50-56. https://doi.org/10.1037/ a0034518

Rivalan, M., Ahmed, S. H., \& Dellu-Hagedorn, F. (2009). Risk-prone individuals prefer the wrong options on a rat version of the Iowa Gambling Task. Biological Psychiatry, 66(8), 743-749. https://doi. org/10.1016/j.biopsych.2009.04.008

Robinson, J., Sareen, J., Cox, B. J., \& Bolton, J. M. (2011). Role of Selfmedication in the Development of Comorbid Anxiety and Substance Use Disorders: A Longitudinal Investigation. Archives of General Psychiatry, 68(8), 800-807. https://doi.org/10.1001/ archgenpsychiatry.2011.75

Robinson, M. J. F., Anselme, P., Fischer, A. M., \& Berridge, K. C. (2014a). Initial uncertainty in Pavlovian reward prediction persistently elevates incentive salience and extends sign-tracking to normally unattractive cues. Behavioural Brain Research, 266, 119-130. https://doi.org/10.1016/j.bbr.2014.03.004

Robinson, M. J. F., Anselme, P., Suchomel, K., \& Berridge, K. C. (2015a). Amphetamine-Induced Sensitization and Reward Uncertainty Similarly Enhance Incentive Salience for Conditioned Cues. Behavioral Neuroscience, 129(4), 502-511. https://doi.org/ 10.1037/bne0000064

Robinson, M. J. F., \& Berridge, K. C. (2015). Wanting vs Needing (pp. 351-356). Elsevier. https://doi.org/10.1016/B978-0-08-097086-8. 26091-1

Robinson, M. J. F., Fischer, A. M., Ahuja, A., Lesser, E. N., \& Maniates, H. (2015b). Roles of "Wanting" and "Liking" in Motivating Behavior: Gambling, Food, and Drug Addictions. In P. D. Balsam \& E. H. Simpson (Eds.), Current Topics in Behavioral Neuroscience (Vol. 27, pp. 105-136). Cham: Current topics in behavioral neurosciences. 10.1007/7854 2015387

Robinson, M. J. F., Robinson, T. E., \& Berridge, K. C. (2013). Incentive Salience and the Transition to Addiction. In Biological Research on Addiction (pp. 391-399). Elsevier. https://doi.org/10.1016/B978-012-398335-0.00039-X

Robinson, T. E., Angus, A. L., \& Becker, J. B. (1985). Sensitization to stress: the enduring effects of prior stress on amphetamine-induced rotational behavior. Life Sciences, 37(11), 1039-1042.

Robinson, T. E., \& Becker, J. B. (1986). Enduring changes in brain and behavior produced by chronic amphetamine administration: a review and evaluation of animal models of amphetamine psychosis. Brain Research, 396(2), 157-198.

Robinson, T. E., \& Berridge, K. C. (1993). The neural basis of drug craving: an incentive-sensitization theory of addiction. Brain Research Brain Research Reviews, 18(3), 247-291.

Robinson, T. E., \& Berridge, K. C. (2008). The incentive sensitization theory of addiction: some current issues. Philosophical Transactions of the Royal Society of London Series B, Biological Sciences, 363(1507), 3137-3146. https://doi.org/10.1098/rstb.2008.0093

Robinson, T. E., \& Flagel, S. B. (2009). Dissociating the Predictive and Incentive Motivational Properties of Reward-Related Cues Through the Study of Individual Differences. Biological Psychiatry, 65(10), 869-873. https://doi.org/10.1016/j.biopsych.2008.09.006

Robinson, T. E., Jurson, P. A., Bennett, J. A., \& Bentgen, K. M. (1988). Persistent sensitization of dopamine neurotransmission in ventral 
striatum (nucleus accumbens) produced by prior experience with (+)-amphetamine: a microdialysis study in freely moving rats. Brain Research, 462(2), 211-222.

Robinson, T. E., Yager, L. M., Cogan, E. S., \& Saunders, B. T. (2014b). On the motivational properties of reward cues: individual differences. Neuropharmacology, 76 Pt B, 450-459. https://doi.org/10. 1016/j.neuropharm.2013.05.040

Rodrigues, A.-J., Leão, P., Carvalho, M., Almeida, O. F. X., \& Sousa, N. (2011). Potential programming of dopaminergic circuits by early life stress. Psychopharmacology, 214(1), 107-120. https://doi.org/10. 1007/s00213-010-2085-3

Rømer Thomsen, K., Fjorback, L. O., Møller, A., \& Lou, H. C. (2014). Applying incentive sensitization models to behavioral addiction. Neuroscience and Biobehavioral Reviews, 45C, 343-349. https:// doi.org/10.1016/j.neubiorev.2014.07.009

Ronzitti, S., Kraus, S. W., Hoff, R. A., \& Potenza, M. N. (2018). Stress moderates the relationships between problem-gambling severity and specific psychopathologies. Psychiatry Research, 259, 254-261. https://doi.org/10.1016/j.psychres.2017.10.028

Rose, J. E., Behm, F. M., Westman, E. C., \& Johnson, M. (2000). Dissociating nicotine and nonnicotine components of cigarette smoking. Pharmacology, Biochemistry, and Behavior, 67(1), 7181.

Saal, D., Dong, Y., Bonci, A., \& Malenka, R. C. (2003). Drugs of Abuse and Stress Trigger a Common Synaptic Adaptation in Dopamine Neurons. Neuron, 37(4), 577-582. https://doi.org/10.1016/s08966273(03)00021-7

Shackman, A. J., Stockbridge, M. D., Tillman, R. M., Kaplan, C. M., Tromp, D. P. M., Fox, A. S., \& Gamer, M. (2016). The neurobiology of dispositional negativity and attentional biases to threat: Implications for understanding anxiety disorders in adults and youth. Journal of Experimental Psychopathology, 7(3), 311-342. https://doi.org/10.5127/jep.054015

Shuster, L., Webster, G. W., \& Yu, G. (1975). Increased running response to morphine in morphine-pretreated mice. Journal of Pharmacology and Experimental Therapeutics, 192(1), 64-67.

Shuster, L., Yu, G., \& Bates, A. (1977). Sensitization to cocaine stimulation in mice. Psychopharmacology, 52(2), 185-190.

Simmons, A., Matthews, S. C., Paulus, M. P., \& Stein, M. B. (2008). Intolerance of uncertainty correlates with insula activation during affective ambiguity. Neuroscience Letters, 430(2), 92-97. https:// doi.org/10.1016/j.neulet.2007.10.030

Singer, B. F., Scott-Railton, J., \& Vezina, P. (2012). Unpredictable saccharin reinforcement enhances locomotor responding to amphetamine. Behavioural Brain Research, 226(1), 340-344. https://doi. org/10.1016/j.bbr.2011.09.003

Sinha, R., Fox, H. C., Hong, K. A., Bergquist, K., Bhagwagar, Z., \& Siedlarz, K. M. (2009). Enhanced negative emotion and alcohol craving, and altered physiological responses following stress and cue exposure in alcohol dependent individuals. Neuropsychopharmacology, 34(5), 1198-1208. https://doi.org/10. 1038/npp.2008.78

Sinha, R., Fox, H. C., Hong, K.-I. A., Hansen, J., Tuit, K., \& Kreek, M. J. (2011). Effects of adrenal sensitivity, stress- and cue-induced craving, and anxiety on subsequent alcohol relapse and treatment outcomes. Archives of General Psychiatry, 68(9), 942-952. https://doi. org/10.1001/archgenpsychiatry.2011.49

Sinha, R., \& Li, C. S. R. (2007). Imaging stress- and cue-induced drug and alcohol craving: association with relapse and clinical implications. Drug and Alcohol Review, 26(1), 25-31. https://doi.org/10. 1080/09595230601036960

Shaffer, H. J., \& Hall, M. N. (2001). Updating and refining prevalence estimates of disordered gambling behaviour in the United States and Canada. Canadian Journal of Public Health $=$ Revue Canadienne De Santé Publique, 92(3), 168-172.
Slutske, W. S., Ellingson, J. M., Richmond-Rakerd, L. S., Zhu, G., \& Martin, N. G. (2013). Shared genetic vulnerability for disordered gambling and alcohol use disorder in men and women: evidence from a national community-based Australian Twin Study. Twin Research and Human Genetics : the Official Journal of the International Society for Twin Studies, 16(2), 525-534. https://doi. org/10.1017/thg.2013.11

Slutske, W. S., Piasecki, T. M., Blaszczynski, A., \& Martin, N. G. (2010). Pathological gambling recovery in the absence of abstinence. Addiction, 105(12), 2169-2175. https://doi.org/10.1111/j.13600443.2010.03080.x

Slutske, W. S., Zhu, G., Meier, M. H., \& Martin, N. G. (2011). Disordered gambling as defined by the Diagnostic and Statistical Manual of Mental Disorders and the South Oaks Gambling Screen: Evidence for a common etiologic structure. Journal of Abnormal Psychology, 120(3), 743-751. https://doi.org/10.1037/a0022879

Small, A. C., Kampman, K. M., Plebani, J., De Jesus Quinn, M., Peoples, L., \& Lynch, K. G. (2009). Tolerance and sensitization to the effects of cocaine use in humans: a retrospective study of long-term cocaine users in Philadelphia. Substance Use \& Misuse, 44(13), 1888-1898. https://doi.org/10.3109/10826080902961179

Song, M., Wang, X. Y., Zhao, M., Wang, X.-Y., Zhai, H. F., \& Lu, L. (2007). Role of Stress in Acquisition of Alcohol-Conditioned Place Preference in Adolescent and Adult Mice. Alcoholism, Clinical and Experimental Research, 31(12), 2001-2005. https://doi.org/10. $1111 / \mathrm{j} .1530-0277.2007 .00522 . x$

Spoelder, M., Tsutsui, K. T., Lesscher, H. M. B., Vanderschuren, L. J. M. J., \& Clark, J. J. (2015). Adolescent Alcohol Exposure Amplifies the Incentive Value of Reward-Predictive Cues Through Potentiation of Phasic Dopamine Signaling. Neuropsychopharmacology, 40(13), 2873-2885. https://doi.org/10.1038/npp.2015.139

Srey, C. S., Maddux, J.-M. N., \& Chaudhri, N. (2015). The attribution of incentive salience to Pavlovian alcohol cues: a shift from goaltracking to sign-tracking. Frontiers in Behavioral Neuroscience, 9 , 1-13. https://doi.org/10.3389/fnbeh.2015.00054/abstract

Steeves, T. D. L., Miyasaki, J., Zurowski, M., Lang, A. E., Pellecchia, G., Van Eimeren, T., et al. (2009). Increased striatal dopamine release in Parkinsonian patients with pathological gambling: a [11C] raclopride PET study. Brain : a Journal of Neurology, 132(Pt 5), 1376-1385. https://doi.org/10.1093/brain/awp054

Stinchfield, R., \& Winters, K. C. (2001). Outcome of Minnesota's gambling treatment programs. Journal of Gambling Studies, 17(3), 217 245.

Tanovic, E., Gee, D. G., \& Joormann, J. (2018). Intolerance of uncertainty: Neural and psychophysiological correlates of the perception of uncertainty as threatening. Clinical Psychology Review, 60, 87-99. https://doi.org/10.1016/j.cpr.2018.01.001

Thalemann, R., Wölfling, K., \& Grüsser, S. M. (2007). Specific cue reactivity on computer game-related cues in excessive gamers. Behavioral Neuroscience, 121(3), 614-618. https://doi.org/10. 1037/0735-7044.121.3.614

Tindell, A. J., Berridge, K. C., Zhang, J., Peciña, S., \& Aldridge, J. W. (2005). Ventral pallidal neurons code incentive motivation: amplification by mesolimbic sensitization and amphetamine. The European Journal of Neuroscience, 22(10), 2617-2634. https://doi.org/10. 1111/j.1460-9568.2005.04411.x

Tomie, A., \& Sharma, N. (2013). Pavlovian sign-tracking model of alcohol abuse. Current Drug Abuse Reviews, 6(3), 201-219.

Tschibelu, E., \& Elman, I. (2011). Gender differences in psychosocial stress and in its relationship to gambling urges in individuals with pathological gambling. Journal of Addictive Diseases, 30(1), 81-87. https://doi.org/10.1080/10550887.2010.531671

Van Bockstaele, B., Verschuere, B., Tibboel, H., De Houwer, J., Crombez, G., \& Koster, E. H. W. (2014). A review of current evidence for the causal impact of attentional bias on fear and anxiety. 
Psychological Bulletin, 140(3), 682-721. https://doi.org/10.1037/ a0034834

van Holst, R. J., Lemmens, J. S., Valkenburg, P. M., Peter, J., Veltman, D. J., \& Goudriaan, A. E. (2012). Attentional bias and disinhibition toward gaming cues are related to problem gaming in male adolescents. The Journal of Adolescent Health : Official Publication of the Society for Adolescent Medicine, 50(6), 541-546. https://doi.org/10. 1016/j.jadohealth.2011.07.006

Versaggi, C. L., King, C. P., \& Meyer, P. J. (2016). The tendency to signtrack predicts cue-induced reinstatement during nicotine self-administration, and is enhanced by nicotine but not ethanol. Psychopharmacology, 233(15-16), 2985-2997. https://doi.org/10. 1007/s00213-016-4341-7

Vezina, P. (2004). Sensitization of midbrain dopamine neuron reactivity and the self-administration of psychomotor stimulant drugs. Neuroscience and Biobehavioral Reviews, 27(8), 827-839. https:// doi.org/10.1016/j.neubiorev.2003.11.001

Vezina, P., Lorrain, D. S., Arnold, G. M., Austin, J. D., \& Suto, N. (2002). Sensitization of Midbrain Dopamine Neuron Reactivity Promotes the Pursuit of Amphetamine. The Journal of Neuroscience: the Official Journal of the Society for Neuroscience, 22(11), 4654 4662. https://doi.org/10.1523/JNEUROSCI.22-11-04654.2002

Vezina, P., McGehee, D. S., \& Green, W. N. (2007). Exposure to nicotine and sensitization of nicotine-induced behaviors. Progress in NeuroPsychopharmacology \& Biological Psychiatry, 31(8), 1625-1638. https://doi.org/10.1016/j.pnpbp.2007.08.038

Volkow, N. D., Wang, G.-J., Fowler, J. S., Logan, J., Jayne, M., Franceschi, D., et al. (2002). "Nonhedonic" food motivation in humans involves dopamine in the dorsal striatum and methylphenidate amplifies this effect. Synapse, 44(3), 175-180. https://doi.org/ 10.1002/syn. 10075

Volkow, N. D., Wang, G.-J., Telang, F., Fowler, J. S., Logan, J., Childress, A. R., et al. (2006). Cocaine Cues and Dopamine in Dorsal Striatum: Mechanism of Craving in Cocaine Addiction. The Journal of Neuroscience, 26(24), 6583-6588.

Walther, B., Morgenstern, M., \& Hanewinkel, R. (2012). Co-Occurrence of Addictive Behaviours: Personality Factors Related to Substance Use, Gambling and Computer Gaming. European Addiction Research, 18(4), 167-174. https://doi.org/10.1159/000335662

Wareham, J. D., \& Potenza, M. N. (2010). Pathological Gambling and Substance Use Disorders. The American Journal of Drug and Alcohol Abuse, 36(5), 242-247. https://doi.org/10.3109/ 00952991003721118

Waters, A. J., Shiffman, S., Sayette, M. A., Paty, J. A., Gwaltney, C. J., \& Balabanis, M. H. (2003). Attentional bias predicts outcome in smoking cessation. Health Psychology : Official Journal of the Division of Health Psychology, American Psychological Association, 22(4), 378-387. https://doi.org/10.1037/0278-6133. 22.4.378

Weinberger, A. H., Franco, C. A., Hoff, R. A., Pilver, C., Steinberg, M. A., Rugle, L., et al. (2015). Cigarette smoking, problem-gambling severity, and health behaviors in high-school students. Addictive Behaviors Reports, 1(C), 40-48. https://doi.org/10.1016/j.abrep. 2015.01.001

West, R. (2009). The Multiple Facets of Cigarette Addiction and What They Mean for Encouraging and Helping Smokers to Stop. COPD: Journal of Chronic Obstructive Pulmonary Disease, 6(4), 277-283. https://doi.org/10.1080/15412550903049181

Wise, R. A., \& Bozarth, M. A. (1987). A psychomotor stimulant theory of addiction. Psychological Review, 94(4), 469-492.

Wulfert, E., Maxson, J., \& Jardin, B. (2009). Cue-specific reactivity in experienced gamblers. Psychology of Addictive Behaviors, 23(4), 731-735. https://doi.org/10.1037/a0017134
Wyvell, C. L., \& Berridge, K. C. (2000). Intra-accumbens amphetamine increases the conditioned incentive salience of sucrose reward: enhancement of reward "wanting" without enhanced "liking" or response reinforcement. The Journal of Neuroscience, 20(21), 8122 8130.

Wyvell, C. L., \& Berridge, K. C. (2001). Incentive sensitization by previous amphetamine exposure: increased cue-triggered "wanting" for sucrose reward. The Journal of Neuroscience, 21(19), 7831-7840.

Yager, L. M., \& Robinson, T. E. (2013). A classically conditioned cocaine cue acquires greater control over motivated behavior in rats prone to attribute incentive salience to a food cue. Psychopharmacology, 226(2), 217-228. https://doi.org/10.1007/s00213-012-2890-y

Yap, J. J., Chartoff, E. H., Holly, E. N., Potter, D. N., Carlezon, W. A., \& Miczek, K. A. (2015). Social defeat stress-induced sensitization and escalated cocaine self-administration: the role of ERK signaling in the rat ventral tegmental area. Psychopharmacology, 232(9), 15551569. https://doi.org/10.1007/s00213-014-3796-7

Zack, M., Featherstone, R. E., Mathewson, S., \& Fletcher, P. J. (2014). Chronic exposure to a gambling-like schedule of reward predictive stimuli can promote sensitization to amphetamine in rats. Frontiers in Behavioral Neuroscience, 8, 36. https://doi.org/10.3389/fnbeh. 2014.00036

Zack, M., \& Poulos, C. X. (2009). Parallel roles for dopamine in pathological gambling and psychostimulant addiction. Current Drug Abuse Reviews, 2(1), 11-25.

Zago, A., Leao, R. M., Carneiro-de-Oliveira, P. E., Marin, M. T., Cruz, F. C., \& Planeta, C. S. (2012). Effects of simultaneous exposure to stress and nicotine on nicotine-induced locomotor activation in adolescent and adult rats. Brazilian Journal of Medical and Biological Research = Revista Brasileira De Pesquisas Medicas E Biologicas, 45(1), 33-37. https://doi.org/10.1590/S0100-879X2011007500153

Zeeb, F. D., Li, Z., Fisher, D. C., Zack, M. H., \& Fletcher, P. J. (2017). Uncertainty exposure causes behavioural sensitization and increases risky decision-making in male rats: toward modelling gambling disorder. Journal of Psychiatry \& Neuroscience, 42(6), 404-413. https://doi.org/10.1503/jpn.170003

Zeeb, F. D., Robbins, T. W., \& Winstanley, C. A. (2009). Serotonergic and Dopaminergic Modulation of Gambling Behavior as Assessed Using a Novel Rat Gambling Task. Neuropsychopharmacology, 34(10), 2329-2343. https://doi.org/10.1038/npp.2009.62

Zhang, J., Berridge, K. C., Tindell, A. J., Smith, K. S., \& Aldridge, J. W. (2009). A neural computational model of incentive salience. PLoS Computational Biology, 5(7), e1000437. https://doi.org/10.1371/ journal.pcbi.1000437

Zimmermann, P., Wittchen, H. U., Höfler, M., Pfister, H., Kessler, R. C., \& Lieb, R. (2003). Primary anxiety disorders and the development of subsequent alcohol use disorders: a 4-year community study of adolescents and young adults. Psychological Medicine, 33(33), 1211-1222. https://doi.org/10.1017/S0033291703008158

Zvolensky, M. J., \& Bernstein, A. (2005). Cigarette Smoking and Panic Psychopathology. Current Directions in Psychological Science, 14(6), 301-305. https://doi.org/10.1111/j.0963-7214.2005.00386.x

Zvolensky, M. J., Bernstein, A., Marshall, E. C., \& Feldner, M. T. (2006). Panic attacks, panic disorder, and agoraphobia: Associations with substance use, abuse, and dependence. Current Psychiatry Reports, 8(4), 279-285. https://doi.org/10.1007/s11920-006-0063-6

Zvolensky, M. J., Stewart, S. H., Vujanovic, A. A., Gavric, D., \& Steeves, D. (2009). Anxiety sensitivity and anxiety and depressive symptoms in the prediction of early smoking lapse and relapse during smoking cessation treatment. Nicotine \& Tobacco Research : Official Journal of the Society for Research on Nicotine and Tobacco, 11(3), 323331. https://doi.org/10.1093/ntr/ntn037 